\title{
Casting Materials and their Application in Research and Teaching
}

\author{
Kati Haenssgen, ${ }^{1}$ Andrew N. Makanya, ${ }^{1,2}$ and Valentin Djonov ${ }^{1 *}$ \\ ${ }^{1}$ Institute of Anatomy, University of Bern, Baltzerstrasse 2, Ch-3000 Bern 9, Switzerland \\ ${ }^{2}$ Department of Veterinary Anatomy \& Physiology, Riverside Drive, Chiromo Campus, University of Nairobi, Box 30197-00100, \\ Nairobi, Kenya
}

\begin{abstract}
From a biological point of view, casting refers to filling of anatomical and/or pathological spaces with extraneous material that reproduces a three-dimensional replica of the space. Casting may be accompanied by additional procedures such as corrosion, in which the soft tissue is digested out, leaving a clean cast, or the material may be mixed with radiopaque substances to allow $\mathrm{x}$-ray photography or micro computed topography $(\mu \mathrm{CT})$ scanning. Alternatively, clearing of the surrounding soft tissue increases transparency and allows visualization of the casted cavities. Combination of casting with tissue fixation allows anatomical dissection and didactic surgical procedures on the tissue. Casting materials fall into three categories namely, aqueous substances (India ink, Prussian blue ink), pliable materials (gelatins, latex, and silicone rubber), or hard materials (methyl methacrylates, polyurethanes, polyesters, and epoxy resins). Casting has proved invaluable in both teaching and research and many phenomenal biological processes have been discovered through casting. The choice of a particular material depends inter alia on the targeted use and the intended subsequent investigative procedures, such as dissection, microscopy, or $\mu \mathrm{CT}$. The casting material needs to be pliable where anatomical and surgical manipulations are intended, and capillary-passable for ultrastructural investigations.
\end{abstract}

Key words: casting material, corrosion, microscopy, teaching, research

\section{INTRODUCTION}

In as far as biological specimens are concerned; casting means the process of filling natural or pathological hollow spaces of a specimen with an extraneous material. In the precorrosion casting era, both air and liquids were used (Aharinejad \& Lametschwandtner, 1992), but currently casting mainly utilizes solidifying or polymerizing materials. In the context of corrosion casting, corrosion refers to removal of the tissue surrounding the casted hollow space, so that the solidified cast depicts the three-dimensional (3D) architecture of the hollow structure, and thus the terminology corrosion casting (Tompsett, 1970; Hodde \& Nowell, 1980). Casting in the concept of biological specimens should be clearly differentiated from casting of archeological zoolites and artifacts in which a replica is created from plaster, resins, or fiber glass (Goodwin \& Chaney, 1994) or from casting as may be applied clinically in management of fractures (Boyd et al., 2009a, 2009b). Although the materials used may be the same, casts in the former case are reproductions of the object, made by pouring a liquid material, such as plaster or a resin into a mold, which has been made from the surface of the specimen. In dentistry, casting refers to the process by which crowns, inlays, and other metallic restorations are produced and may employ metals such as gold or titanium (Geurtsen, 2002).

Received October 25, 2013; accepted December 4, 2013

*Corresponding author. valentin.djonov@ana.unibe.ch

\section{BRIEF HISTORY}

Since the description of arteries by Herophilus of Alexandria (325-255 BC), who performed the first ever human cadaver dissections (Wiltse \& Pait, 1998), the need to understand the body vasculature and indeed hollow organs has heightened. Galen (circa 129-200 AD) established the basis of modern anatomy by compiling much of the knowledge obtained by performing dissections on animals and collections of drawings, based mostly on dog anatomy, which became the anatomy textbook for 1,500 years. The use of casts to visualize and describe morphological features of biological specimens is an old technique dating back to the 14th century when Alessandra Giliani, a young prosector, used colored liquids to view blood vessels (Aharinejad \& Lametschwandtner, 1992). The technique of wax modeling was already known to the Greeks and Romans but the first documented evidence in teaching anatomy was by Alessandra Giliani in Bologna, where she was a master in wax injection techniques. About a century later, Andrea del Verrocchio (1435-1488) was the first to make casts of the living body as models for schools and this apparently stimulated his pupil Leonardo de Vinci (1452-1519) to make wax casts of the ventricles of the brain (Cooke, 2010). In the subsequent years, investigators continued to use space filing substances including water, air, milk, ale, saffron, and ink. Swammerdam (1637-1680) injected colored wax in arteries and veins and other materials including starch, plaster of Paris, glue, glazier's putty, asphalt, gum Arabic (acacia gum), sodium silicate, sesame oil, shellac, 
thymol, and mercury (Wiltse \& Pait, 1998). These investigators used casting without corrosion and this period is referred to as the precorrosion casting era (Aharinejad \& Lametschwandtner, 1992).

The corrosion casting era started much later when Bidloo (1685) used Rose's metal (alloy of bismuth, lead, and tin) as an injectable and boiled the specimen to remove connective tissues (Bidloo, 1685; Kemp, 2010). In 1704, Ruysch injected metal into coronary vessels and used maggots and larvae to clear the soft tissues, thus obtaining a vascular cast. Subsequently use of chemicals to digest the soft tissues was employed and this was pioneered by Lieberkuhn (1711-1746), who used acid as a corrosion medium to eliminate soft tissues (Bergeron et al., 2006). Various mixtures of casting materials have since been used with different types of corrosion agents such as hydrochloric acid or potassium hydroxide (Wiltse \& Pait, 1998). To date, corrosion casting is a thriving field in biomedical sciences (Bergeron et al., 2006) and museum technology (Makanya et al., 2008).

\section{Brief Overview of Uses of Casting MAterials}

Casting materials may be used in three different ways: (1) preparation of specimens in basic and investigative research; (2) preparation of specimens for anatomical teaching or for enhancement of skills for clinicians and surgeons; (3) preparation of museum specimens for preservation and display. The choice of the appropriate casting material is determined by a variety of factors, such as the purpose of the final casts and the kind of biological specimen or tissue involved. The possibilities range from low-viscosity, hard materials, such as mercox used for casting the tracheal system of insect species (invertebrates) (Meyer, 1989) to flexible latex rubber used for casting the respiratory system and air sacs of avian species (vertebrates) (Akester, 1960).

\section{Casts for Teaching}

Casts for anatomical courses aim to elucidate otherwise complex anatomical spatial relationships (Henry et al., 1998) and proffer 3D information not readily discernible from two-dimensional (2D) pictures or gross specimens. Such 3D replica are based on real specimens to support the learning process (Aultman et al., 2003) rather than learning from theoretical descriptions (Henry, 1992). Materials used in producing casts for anatomical studies need to be compatible with the subsequent procedures that aim to make the casts even more manageable, such as plastination or impregnation. Both flexible casting materials and hard materials are used for this process. Combined with the new anatomical preservation methods where the cadaver closely resembles the real life situation (Groscurth et al., 2001; Kerckaert et al., 2008), casting has greatly enhanced the ease of studying anatomy.

The training of new surgical approaches may require practice on isolated specimens with blood vessels cast in a conspicuous colored material. Since freezing and thawing does not alter the consistency of soft tissue organs such as the liver, it was demonstrated that such organs combined with casting made them useful material for surgical practice (Ravnik et al., 1995). Indeed corrosion casts of livers were used to study the 3D structure of hepatic vessels and bile ducts before the surgical techniques were clinically applied (Ravnik et al., 1995). Detailed knowledge of the course, diameters, branches and possible variants of vessels is requisite in surgical organ resection and training of surgeons on such details (Kawarada et al., 2000; Onishi et al., 2000). Vessels filled with appropriate casting materials greatly enhance the visualization of their distribution. Such casts provide valuable information for many surgical fields, such as reconstructive surgery and neurosurgery for human and veterinary purposes. Vessel-filled specimens are often intended for further procedures, such as dissection, which require flexible casting materials. Aqueous solutions are also used, in particular for the visualization of vascular skin territories. The value of casts may be further enhanced by adding radiopaque materials, which allow the use of imaging techniques such as computed tomography (CT) or magnetic resonance imaging (MRI).

\section{Casts for Research}

Casts for research at the macroscopic level allow visualization of the 3D organization of structures and their topographical position in normal and pathological conditions. At microscopic and ultrastructural levels casting allows investigation of fine structures such as capillaries. At this level the viscosity of the casting materials should be such that they are capillary-passable. In the latter situation, corrosion casting and scanning electron microscopy (SEM) allow study of fine structures such as vascular beds in healthy and pathological tissues and the characteristics of vessels by analyzing the imprints of cells and nuclei left on the surface of the cast (Jamous et al., 2005; Pitynski et al., 2012). Previously we used mercox casting and SEM to demonstrate augmentation of avian renal glomeruli through intussusceptive vascular splitting (Makanya et al., 2005) as well as microvasculature expansion of avian lungs through pillar formation (Makanya et al., 2007). Casting materials used for macroscopic purposes comprise flexible and hard materials, but do not necessarily need to be capillary-passable.

\section{Casting of Museum Specimens}

Casting is one of the numerous procedures used to prepare museum specimens for preservation and presentation (Pulvertaft, 1950; Krucker et al., 2006; Makanya et al., 2008). The materials and procedures used for casting in this case depend on several factors including the preservation status of the specimen when first found and the specific purpose for which the cast is being made. Basically, where the curator has the leeway to choose and prepare specimens, all casting materials and procedures are applicable for museum specimens. 
Table 1. Details of the Various Types of Casting Materials and Their General Characteristics.

\begin{tabular}{|c|c|}
\hline Group & Description \\
\hline \multicolumn{2}{|c|}{ Water-miscible materials } \\
\hline India ink & $\begin{array}{l}\text { Basic India ink is composed of a variety of fine soot known as lampblack, combined with water to } \\
\text { form a liquid }\end{array}$ \\
\hline Prussian blue ink & $\begin{array}{l}\text { Prussian blue (ferric ferrocyanide) was one of the first synthetic pigments ever discovered. It is } \\
\text { employed as a very fine colloidal dispersion since it is not soluble in water }\end{array}$ \\
\hline \multicolumn{2}{|l|}{ Pliable materials } \\
\hline Gelatin & $\begin{array}{l}\text { Gelatin is a translucent, colorless, brittle flavorless solid substance, derived from collagen. It is a } \\
\text { mixture of peptides and proteins produced by partial hydrolysis of collagen }\end{array}$ \\
\hline Latex & $\begin{array}{l}\text { Latex is a complex emulsion consisting of proteins, alkaloids, starches, sugars, oils, tannins, resins, and } \\
\text { gums that coagulates on exposure to air }\end{array}$ \\
\hline Silicone rubber & $\begin{array}{l}\text { Silicone rubber is an elastomer (rubber-like material) composed of silicone, itself a polymer } \\
\text { containing silicon together with carbon, hydrogen, and oxygen. Silicone rubber is generally } \\
\text { non-reactive, stable, and resistant to extreme environments and temperatures from }-55 \text { to }+300^{\circ} \mathrm{C} \\
\text { while still maintaining its useful properties }\end{array}$ \\
\hline \multicolumn{2}{|r|}{ 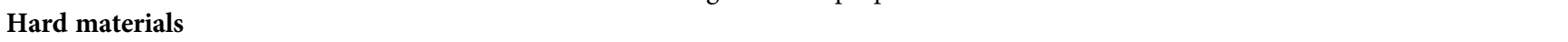 } \\
\hline Methyl methacrylates & $\begin{array}{l}\text { Methyl methacrylate is an organic compound with the formula } \mathrm{CH}_{2}=\mathrm{C}\left(\mathrm{CH}_{3}\right) \mathrm{COOCH}_{3} \text {. This } \\
\text { colorless liquid, the methyl ester of methacrylic acid (MAA) is a monomer produced on a large } \\
\text { scale for the production of poly(methyl methacrylate) (PMMA) }\end{array}$ \\
\hline Epoxy resins & $\begin{array}{l}\text { Epoxy is both the basic component and the cured end product of epoxy resins. Epoxy resins, also } \\
\text { known as polyepoxides are a class of reactive prepolymers and polymers, which contain epoxide } \\
\text { groups. They may be reacted (cross-linked) either with themselves through catalytic } \\
\text { homopolymerisation, or with a wide range of co-reactants including polyfunctional amines, acids } \\
\text { (and acid anhydrides), phenols, alcohols, and thiols }\end{array}$ \\
\hline Polyurethanes & $\begin{array}{l}\text { Polyurethane (PUR and PU) is a polymer composed of a chain of organic units joined by carbamate } \\
\text { (urethane) links. While most polyurethanes are thermosetting polymers that do not melt when } \\
\text { heated, thermoplastic polyurethanes are also available }\end{array}$ \\
\hline Polyester resins & $\begin{array}{l}\text { This is a group of unsaturated organic compounds formed by the reaction of dibasic organic } \\
\text { acids and polyhydric alcohols. Polyester resins are thermosetting and cure exothermically. } \\
\text { The use of excessive catalyst can, therefore, cause charring or even ignition during the } \\
\text { curing process }\end{array}$ \\
\hline
\end{tabular}

\section{Diversity of Casting Materials}

In the past, many types of materials were attempted for casting and such included air, water, milk, and wax (Bergeron et al., 2006; Grabherr et al., 2007). Currently, the arsenal of materials used has been refined to a few highly effective casting media with great scientific significance as well as a strong practical impact. The casting materials used nowadays can be grouped into three categories (Table 1). These include: (1) aqueous solutions (India ink, Prussian blue); (2) flexible materials (gelatin, latexes, and silicone rubbers) and (3) hard, dimensionally stable materials (methylmethacrylates, epoxy resins, polyurethanes, and polyesters).

\section{Uses and Application of Casting MATERIALS}

\section{Water Miscible Materials}

Water miscible materials commonly used in casting include India ink (also known as China ink), Prussian blue ink and latex. Though latex is included here, it is best discussed under pliable materials due to its superior elastic nature.

\section{India Ink}

India ink is composed of a variety of fine soot (lampblack) combined with water to form a liquid. A binding agent such as gelatin (Zhao et al., 2004) or shellac may be added to make it more viscous and more durable once dried. India ink is easily miscible with water and has been used for angiography (Fujimoto et al., 2013), for enhancing clinical and surgical procedures (Shaari et al., 1999) and in casting (Zhao et al., 2004). The problem with aqueous solutions is their possible penetration of neighboring vascular territories via "choke vessels." Choke vessels are arteries with reduced diameters that link adjacent vascular territories and that only dilate during times of increased demand for blood flow (Ye et al., 2012) making assessments of the exact borders of vascular territories difficult (Bergeron et al., 2006; Benzioni et al., 2009). India ink is easily miscible with other casting materials. When mixed with water, the specimen can be fixed in $8 \%$ formaldehyde (Kachlik et al., 2010) and this allows dissection.

Mixing India ink with latex (Parke, 2004; McKeon et al., 2012) improves on viscosity and pliability. Specimens filled with a mixture of India ink and latex are suited for applying the modified Spalteholz technique, which results in 

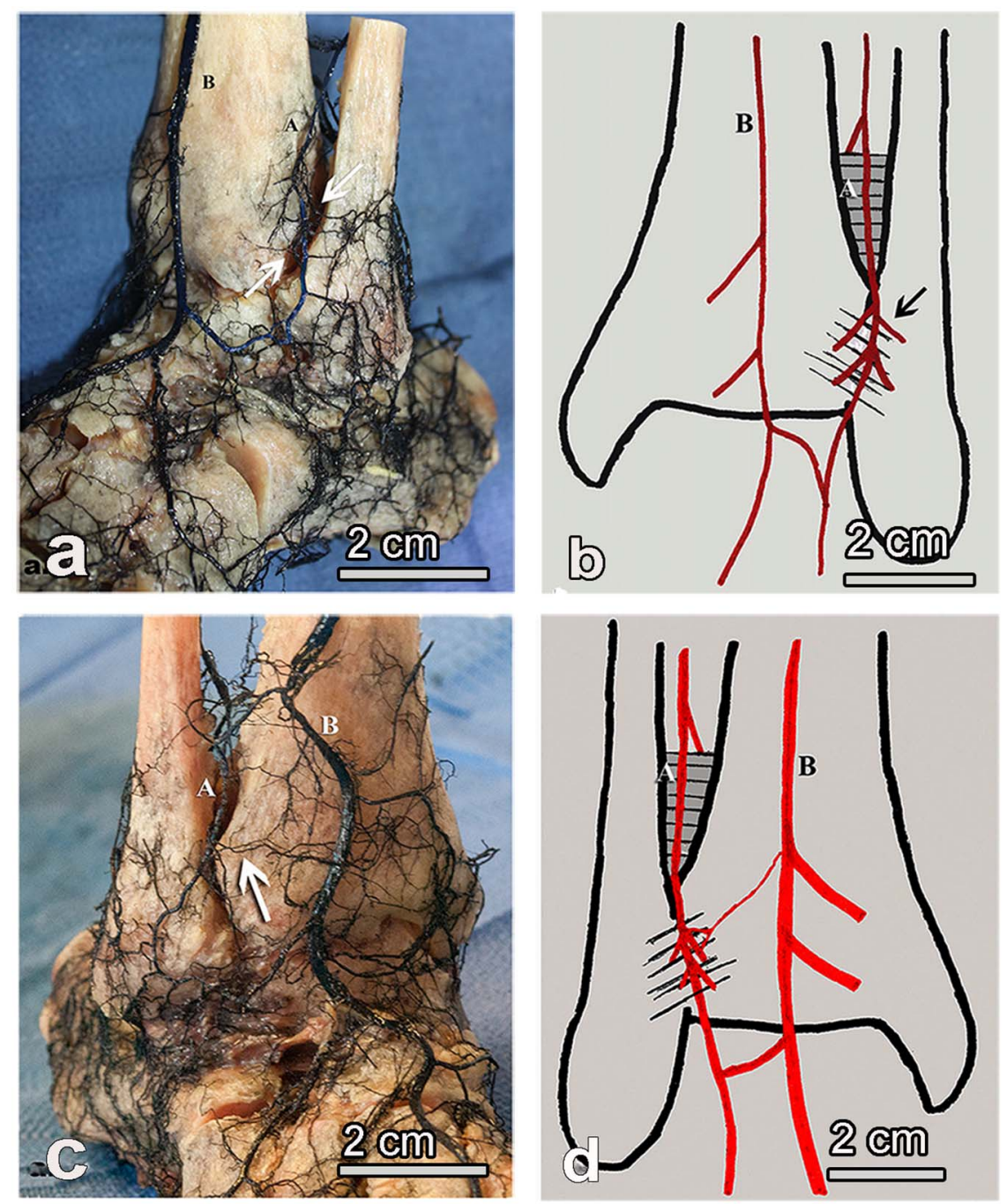

Figure 1. Photographs from India ink and latex vascular casts demonstrating the anterior type 1 and 2 modes of blood supply to the human tibulofibular syndesmosis. The schema is drawn from the casts to emphasize the details. Photograph (a) and line drawing (b) showing Anterior Type 1. In this case the anterior syndesmosis is supplied by the perforating branch of the peroneal artery (A) with multiple small branches (arrows) at the level of the syndesmosis. There is no contribution of the anterior tibial artery (B) at the level of the syndesmosis. Photograph (c) and line drawing (d) showing Anterior Type 2 mode of blood supply. The anterior syndesmosis is supplied by the perforating branch of the peroneal artery (A) with multiple small branches (arrow) at the level of the syndesmosis. The anterior tibial artery (B) also provides small branches to supplement the peroneal contribution to the anterior ligaments. Modified from McKeon et al. (2012), reproduced with permission from The Journal of Bone and Joint Surgery. 94, 931-938. Copyright (c) 2012 Wolters Kluwer Health, Inc. Scale bar is $2 \mathrm{~cm}$.

a transparent specimen that allows visualization of the casted structures. Tilotta et al. (2009) used this technique to visualize the arteries supplying human auricles as did Parke on the arteries supplying the human spinal cord (Parke, 2004). As demonstrated in Figure 1, the vascular supply to the anterior tibiofibular syndesmosis in the adult human leg was visualized by first injecting India ink followed by blue latex (McKeon et al., 2012). Injection is performed in a fresh specimen followed by fixation in formaldehyde (Parke, 2004; Kachlik et al., 2010). Using this technique, it was demonstrated that the peroneal artery supplies an anterior branch (the perforating branch) to the interosseous membrane, an average of $3 \mathrm{~cm}$ proximal to the ankle joint. This branch provided the primary vascular supply to the anterior ligaments in $63 \%$ of subjects studied. The anterior tibial artery provided an additional contribution to the anterior ligaments in the remaining 37\% of the subjects (McKeon et al., 2012).

\section{Prussian Blue}

Prussian blue (Berlin blue) was one of the first synthetic pigments in history. It is a dark blue pigment with the idealized formula $\mathrm{Fe}_{7}(\mathrm{CN})_{18}$ and a complex composition (Berrie, 1997). It is employed as a very fine colloidal dispersion, as the compound itself is not soluble in water. One part Prussian blue ink may be diluted in five parts tap water and injected using extension tubing (Papakonstantinou et al., 2012). Dilution of the Prussian blue ink with hydrogen 
peroxide (6\%) produces casts with better consistency (Papakonstantinou et al., 2012).

\section{Pliable Materials}

Pliable materials are of particular importance for clinical purposes as they can be mixed with radiopaque materials enabling radiographic investigations as well as allowing further dissection (Sedlmayr \& Witmer, 2002). Table 2 shows examples of applications, where radiopaque material was suspended in pliable casting materials for use in CT and MRI to produce angiograms, which enable compilation of $3 \mathrm{D}$ reconstructions. Common radiopaque materials are barium sulfate and lead oxide as well as iodine-containing contrast agents. Lead oxide is variously known under names such as red lead (Bergeron et al., 2006), minium (Plaisant et al., 1998), mennige, and lead (II, IV)-oxide (Thiel, 1992b). The advantage of using lead oxide as a radiopaque material is that it is cheap and easy to apply. Pliable materials have one advantage in that combined with the latest cadaver fixation techniques, they allow both anatomical dissection and training on surgical skills and the specimens can be used over and over again (Groscurth et al., 2001; Kerckaert et al., 2008).

\section{Gelatin}

Gelatin is a colorless, odorless, translucent substance derived from collagen. It requires warm conditions to maintain viscosity at a level appropriate for injection, around $40^{\circ} \mathrm{C}$ but not higher than $50^{\circ} \mathrm{C}$, since higher temperatures result in denaturation of gelatin. The lower temperature is the limit for appropriate viscosity to reach fine vessels. Pre-warming and/or keeping the specimen in warm water enables easier injection of gelatin as was demonstrated by Bergeron et al. (2006) on whole human cadavers. Care should be taken when dealing with formaldehyde-fixed specimens since gelatin quickly hardens in the presence of formaldehyde (Tompsett, 1970; Bergeron et al., 2006). In such a situation irrigation to flush-out formaldehyde (see below) may be necessary. Gelatin can be mixed with dyes to enhance the visibility of the casted structures. It was mixed with a red dye to demonstrate the three types of vasculature on the medial aspect of the human foot (Zhuang et al., 2011). The latter technique combined fixation with casting (Fig. 2) and since gelatin is pliable, it allowed dissection of the soft tissues to enable visualization of the vessels.

Gelatin may be mixed with dyes such as methylene blue (Heymans et al., 2004). It is miscible with radiopaque materials (Table 2) such as barium sulfate or lead oxide (Bergeron et al., 2006), in which case it allows further investigative techniques such $\mathrm{x}$-ray, $\mu \mathrm{CT}$ or even MRI. A mixture of gelatin and lead oxide enabled 3D visualization of various parts of the body in a layer-by-layer transparent process using spiral CT and a special software (Tang et al., 2008). For specimens intended for plastination, gelatin is of limited value since casts end up being brittle, cracked, and stuck to the tissues subsequent to plastination (Grondin et al., 2000). Although plastination and casting may use

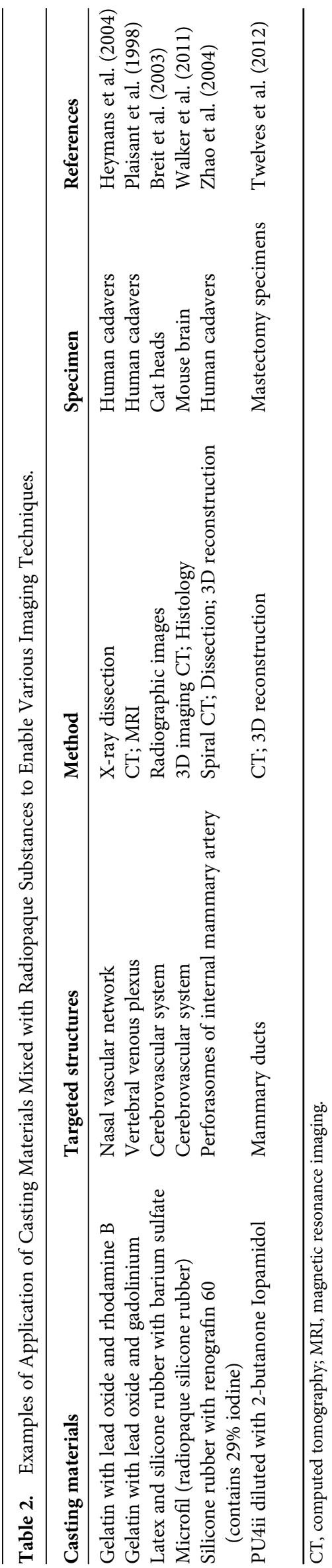



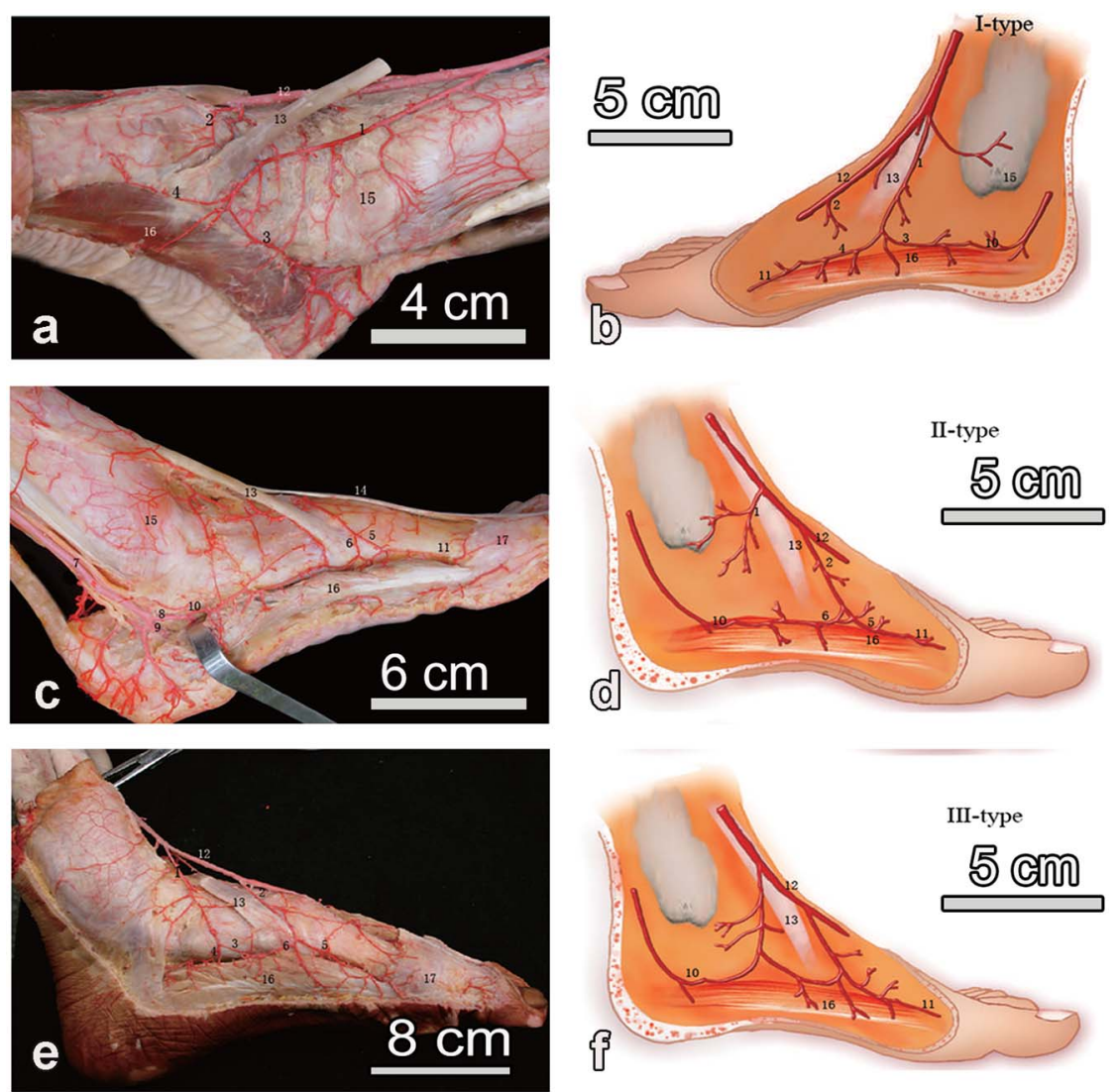

Figure 2. Three types of vasculature on the medial aspect of the human foot demonstrated using gelatin casting and explicated in the respective schema. a, b: Type I; (c, d): type II; (e, f): type III. The structures labeled are: 1, anterior medial malleolar; 2, medial tarsal; 3, posterior branch of the anterior medial malleolar artery; 4, anterior branch of the anterior medial malleolar artery; 5, anterior branch of the medial tarsal artery; 6, posterior branch of the medial tarsal artery; 7, posterior tibial artery; 8, medial plantar artery; 9, lateral plantar artery; 10, superficial branch of the medial plantar artery; 11, proximal superficial branch of the first plantar metatarsal artery; 12, dorsal pedal artery; 13, tendon of the tibialis anterior muscle; 14, tendon of the extensor hallucis longus muscle; 15, medial malleolus; 16, abductor hallucis; 17, first metatarsophalangeal joint. Obtained from Zhuang et al. (2011), reproduced with permission from Plastic and Reconstructive Surgery, 127, 1967-1978. Copyright (C) 2011 Wolters Kluwer Health. Scale bars: (a), 4 cm; (c), 6 cm; (e), 8 cm; (b, d, f), 5 cm.

similar polymers, the two processes are fundamentally different (Grondin, 2005). Plastination entails dehydration, saturation with an appropriate intermediary solvent, and infiltration with an in-cured polymer in vacuo (Bickley et al., 1981). The polymer replaces intracellular tissue water and lipids (Tiedemann \& von Hagens, 1982) and a hollow or cavity need not be present.

\section{Silicone Rubber Casting}

Silicone rubber is an elastomer (elastic polymer) composed of silicone, itself a polymer containing silicon together with carbon, hydrogen, and oxygen. Silicone rubber is generally nonreactive, stable, and resistant to extreme environments and temperatures from -55 to $+300^{\circ} \mathrm{C}$ while still maintaining its useful properties. It may be mixed with dyes of different colors to map out various systems in the same organ (Figs. 3 and 4) and may be combined with other procedures such as tissue fixation (Fig. 4) in which case dissection is also possible. Silicone monomer is first mixed with the dye of choice and then the silicone hardener is added before injection (Makanya \& Djonov, 2008). To improve viscosity, silicone oil (polydimethylsiloxane) may be added
(Perry et al., 2000; Makanya \& Djonov, 2008). Silicon rubber was used to study avian lung air conduits (Makanya \& Djonov, 2008; Makanya et al., 2014) in which case its flexibility allowed for identification and counting of the various categories of secondary bronchi (Fig. 3).

Specimens exhibiting definite pathological conditions, such as obstructed airways or dilated mucous glands may be difficult to cast with silicone. Perry et al. (2000) adopted a method known as a negative-pressure casting technique to force silicone rubber into segments of pathological lungs. When mixed with radiopaque substances such barium sulfate (Table 2), it becomes firm and allows diverse techniques such as $\mathrm{x}$-ray analysis (Nöller et al., 2006) to be undertaken. The dosage of the hardener affects polymerization times and hence injection times. Kaya et al. (2006) describe a method where the mixture of silicone rubber and catalyst hardens within $1 \mathrm{~h}$, which proved to be particularly useful in forensic departments since casting and autopsy procedures could be undertaken simultaneously.

Modified methods of Spalteholtz may be employed to enable tissue clearing and hence visualization of silicone 

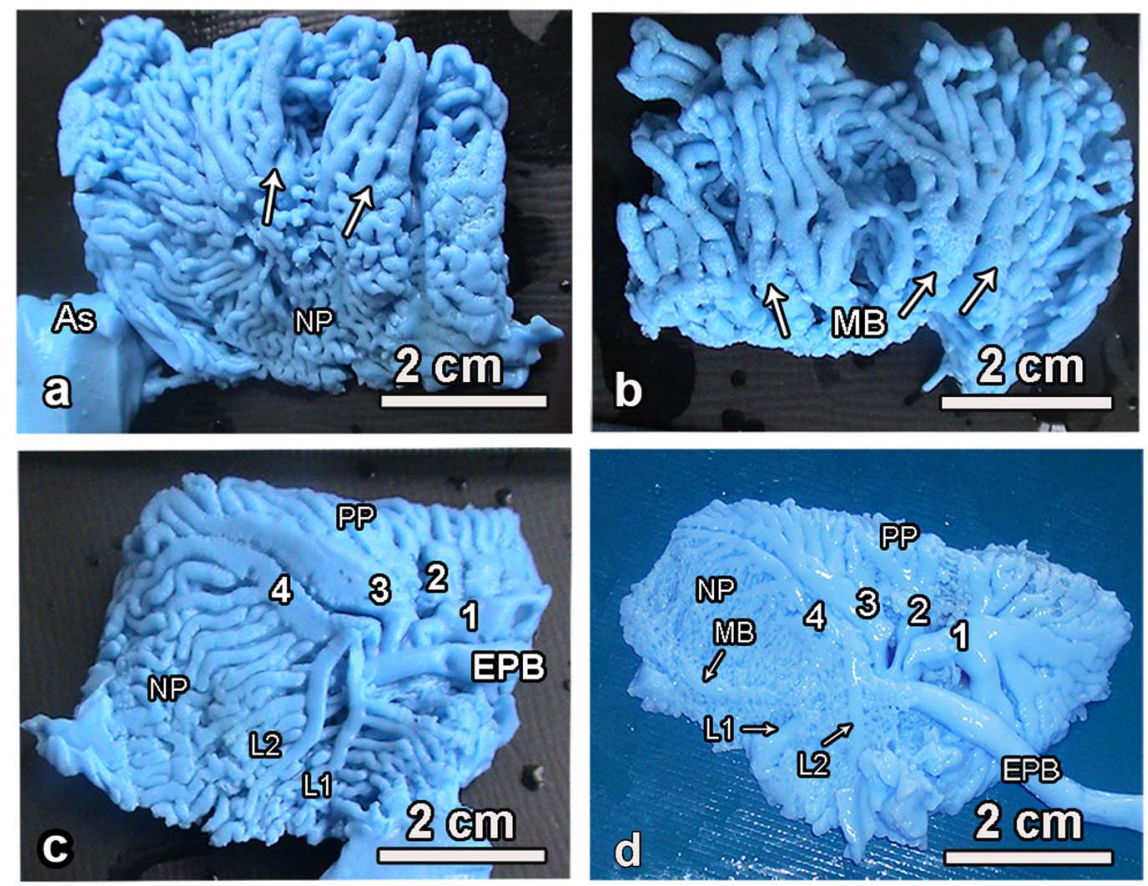

Figure 3. Macrographs of silicone rubber casts explicating the lung structure in the adult chicken (a-c) and duck (d). The laterodorsal secondary bronchi (arrows) are visible on the lateral aspect of the lung. The mesobronchus (MB) the neopulmonic region (NP) and the air sac (As) are also shown. (c, d): On the medial aspect the extrapulmonary primary bronchus (EPB, the medioventral secondary bronchi (1-4), and the lateroventral bronchi (L1 and L2 are shown). The other abbreviations are is in A and B above while PP denotes paleopulmonic region. Figures a-c are modified, reproduced with permission from Microscopy Research and Technique. 106, $1959-1969$. Copyright (C) 2008 Wiley-Liss, Inc. from Makanya and Djonov (2008), while (d) is from Makanya et al., (2014). Scale bar is $2 \mathrm{~cm}$.

rubber-filled vascular networks in tissues (Kappler et al., 2005). Using transparency methods and dyes can have a profound effect. Red-colored Microfil, for example, can be better seen in translucent brain tissue while yellow-colored Microfil is more prominent in translucent myocardium (Walker et al., 2011).

Silicone rubbers are suitable for subsequent postcasting procedures such as plastination as demonstrated with casts of the ventricular system (Grondin et al., 2000). Loss of color intensity during treatment in the acetone bath, a critical step in plastination, may be an undesirable outcome (Pereira-Sampaio et al., 2011). The colored pigments should be mixed with the diluent, if possible, before adding it to the casting material as recommended for silicone rubber (Smith \& Rhoton, 1999).

Henry et al. (1998) produced casts of canine hearts with silicone rubber to show the overlapping spatial relationship of cardiac chambers to first year veterinary students. Having the students do the casting themselves greatly enhances understanding of the structure as was demonstrated with the constructivist approach to study cardiovascular and respiratory morphology (Hermiz et al., 2011). In the latter case, the bronchial tree and coronary arteries of rats were casted with silicone rubber by medical students, the teacher's role being only facilitative (Hermiz et al., 2011).

\section{Latex Casting}

Latex is a complex emulsion consisting of proteins, alkaloids, starches, sugars, oils, tannins, resins, and gums that coagulates on exposure to air. Latex exists as an emulsion of polymer microparticles in an aqueous medium and is thus miscible with water. The color of latex makes it easier to identify casted structures during dissection and its elasticity helps preserve structural integrity. It occurs in a liquid form and solidifies quickly in the presence of formalin (Bergeron et al., 2006). This happens through a process called emulsion polymerization, where propagation reaction of free radicals with monomer molecules in a very large number of discrete polymer particles occurs (Chern, 2006). In standard latex casting of blood vessels, blood is flushed out and latex is injected in the arterial system and allowed to distribute for a few minutes. Subsequent injection of formalin in the venous system enhances the hardening process of the latex (Bergeron et al., 2006). Injection of formalin before latex is also used but is less reliable. An easier and more common procedure is to fix samples in formalin after casting. For example, to demonstrate radiculomedullary arteries in human cadavers in the lumbar region (Fig. 4), samples casted with latex were kept in $20 \%$ formalin at $20^{\circ} \mathrm{C}$ for $2-4$ weeks (Gao et al., 2013), while Nikolić and colleagues used $10 \%$ formaldehyde solution to fix latex-casted hearts (Nikolic et al., 2004).

Modifications are also possible with latex casting. For example, barium sulfate was mixed with latex to produce casts of the nasolacrimal ducts in cats without major artifacts (Breit et al., 2003), and this enabled radiography. An acceptable CT-density was achieved by mixing lead oxide (minium) with latex and for investigation using MRI, gadolinium 

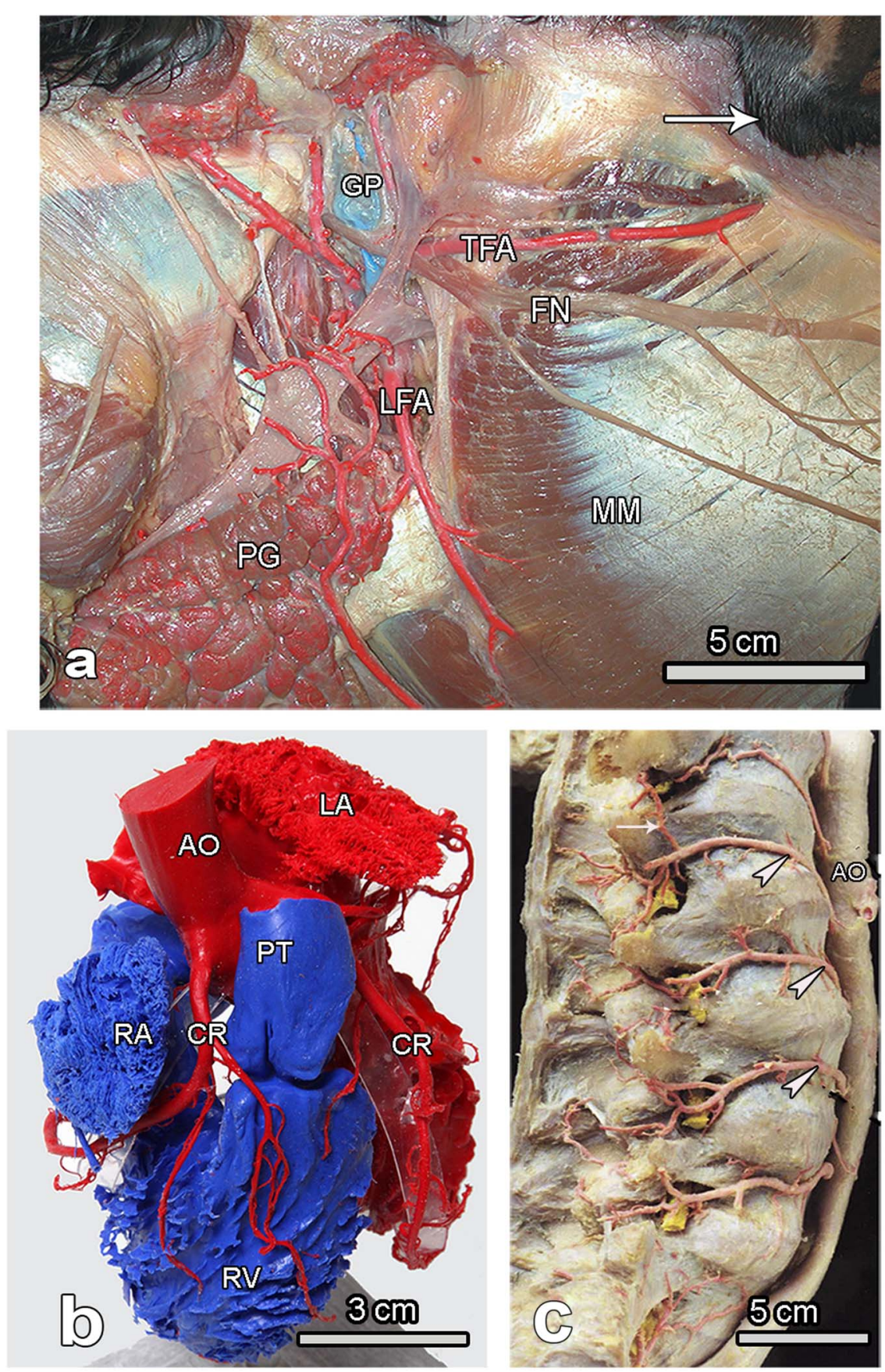

Figure 4. Macrographs demonstrating silicon casting (a, b) and latex casting (c). a: Fixed equine head (lateral view), with vascular silicone casting showing superficial layer of the parotid gland (PG), transverse facial artery (TFA) and the linguofacial artery (LFA). The guttural pouch (GP) has been casted with blue silicone. The facial nerve (FN) and the masseter muscle (MM) are also shown. The arrow indicates the position of the eye. b: Corrosion cast of pig heart, casted with blue (right heart) and red (left heart) silicone to show the coronary arteries (CR), the right atrium (RA), right ventricle (RV), pulmonary trunk (PT), left atrium (LA) and the aorta (AO). c: Lateral view of human lumbar spinal column showing the lumbar arteries (arrow heads) and their anastomosis. The arrow points to the anastomosis of segmental arteries in thoracolumbar region and AO denotes the aorta. a, b: Unpublished data from our laboratory while (c) is reproduced from Gao et al., (2013), reproduced with permission from The Spine Journal, 13, 966-973. Copyright () 2013 Elsevier Limited. Scale bar: (a, c), $5 \mathrm{~cm}$; (b), $3 \mathrm{~cm}$.

(a silvery-white, malleable and ductile rare-earth metal) was added to latex (Plaisant et al., 1998).

Viscosity of latex may be modified by addition of diluents. Diluents for latex include water (Alvernia et al., 2010), ammonium hydroxide, or triethylamine (Thiel, 1992).
Addition of diluting agents results in longer postinjection setting periods (Alvernia et al., 2010). Formalin, ethanol and diluted acid solutions cause latex to solidify (Mulisch \& Welsch, 2010). Latex is available in different colors but can also be colored with poster paint or pigment paste 
(Latorre et al., 2001). Here, caution is advised as the application of alternative dyes might interfere with certain steps of plastination, if such a subsequent procedure is intended. A loss of color-intensity was experienced in the smallest latex-filled structures of plastinated equine forelimbs (Latorre et al., 2001), probably because the pigment used was not color-stable. Regarding plastination, it is noteworthy that latex can swell in methylene chloride (Henry et al., 1997), which is used to saturate specimens just before in vacuo impregnation (von Hagens, 1979; Bickley et al., 1987). Use of acetone as a saturation medium rather than methylene chloride does not appear to engender swelling of latex (Latorre et al., 2001). Clearing, which makes the structures surrounding the cast transparent, can be achieved by treatment with glycerin, thus allowing visualization of the latex-filled arterial network within the tissues (An et al., 2012).

\section{Hard Materials}

Hard casting materials comprise methacrylates, polyurethanes, epoxy resins, and polyesters. Polyurethanes, though classified here as hard materials, can also be used as flexible casts in dissection. Both methacrylates and polyurethanes are generally capillary-passable and have been used in macroscopic as well as ultrastructural investigations.

\section{Methacrylate Casting}

Methacrylates are monomers in polymer plastics and form the acrylate polymers, which are known to be elastic, transparent and resistant to breakage. They easily form polymers because they possess very reactive double bonds in their chemical structure. The term methacrylate refers to derivatives of methacrylic acid, including the parent acid $\left(\mathrm{CH}_{2} \mathrm{C}\left(\mathrm{CH}_{3}\right)\right.$ $\mathrm{CO}_{2} \mathrm{H}$ ), salts, esters or methyl methacrylate and the polymers of these species. Methacrylates are generally capillary-passable and have been used in both macroscopic (Fig. 5) and ultrastructural (Fig. 6) investigations. They can be mixed with dyes of varied colors to outline several different tubular systems of the same organ as demonstrated for the pig kidney (Fig. 5). Alternatively, different casting materials may be used in the same biological specimen, hence providing information of comparative value. Nöller et al. described the casting of paranasal sinuses of fresh cat heads with Technovit 7143 and Tensolcement 70. Problems occurred with both casting materials; Technovit 7143 (ratio of powder to liquid 2:1) required quick injection and the resulting casts proved to be very brittle and Tensolcement 70 seemed to be less suited for filling such large cavities. The mixture settled due to its longer curing time, which made re-injection necessary (Nöller et al., 2006).

Waldmann (2006) applied Technovit 7143 into the arteries (ratio of powder to liquid 1.7:1) and Mercox into the veins of the forelimb in common wood pigeons (Columba palumbus). Mercox, in contrast to Technovit 7143, was able to overcome the venous valves, thus filling even the small capillaries, which necessitated removal of the smaller vessels from the final cast, since they were not required
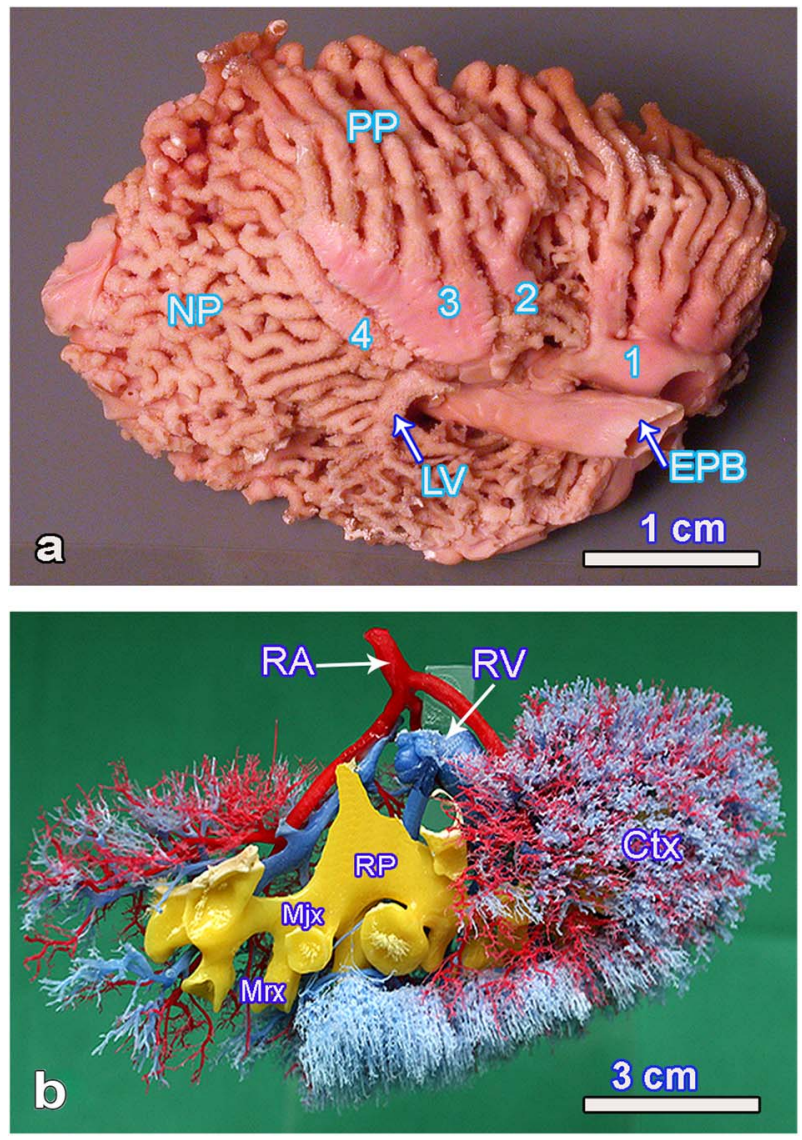

Figure 5. Technovit 3040 cast of the adult chicken lung showing the medioventral aspect. The primary bronchus (EPB), the medioventral secondary bronchi (1-4), and the lateroventral secondary bronchus (LV) are shown. Note also the neopulmonic (NP) and paleopulmonic (PP) parabronchial regions. b: Corrosion cast of pig kidney, produced from Technovit 7143 during student optional courses, with arteries injected with red, veins with blue and urinary system with yellow resin. The renal pelvis (RP), major calyces (Mjx) and the minor calyces (Mrx) represent the urinary system. The renal artery (RA), the renal vein (RV) and the kidney cortex (Ctx) are also shown. A is modified from Makanya and Djonov (2008). Reproduced with permission from Microscopy Research and Technique. 71, 689-702. Copyright (c) 2008 Wiley-Liss, Inc. while B is unpublished data. Scale bar: (a), $1 \mathrm{~cm}$; (b), $3 \mathrm{~cm}$.

(Waldmann, 2006). Technovit 7143 was observed to be brittle compared to Mercox (Waldmann, 2006). Mercox is popular for utrastructural studies and together with SEM has been used for more than five decades (Hossler \& Douglas, 2001). Its capacity to fill even the small capillaries has enabled its use in demonstration of incipient vasculature (Fig. 6) both by demonstration of new capillary sprouts (Makanya et al., 2007) as well as intussusceptive pillars (Caduff et al., 1986).

\section{Polyurethane Casting}

Polyurethane (PU, Pu4ii) is a polymer made up of a chain of organic units joined by urethane links. Polyurethane polymers are formed by reacting an isocyanate $(\mathrm{R}-\mathrm{N}=$ $\mathrm{C}=\mathrm{O})$ with a polyol. Both the isocyanates and polyols 

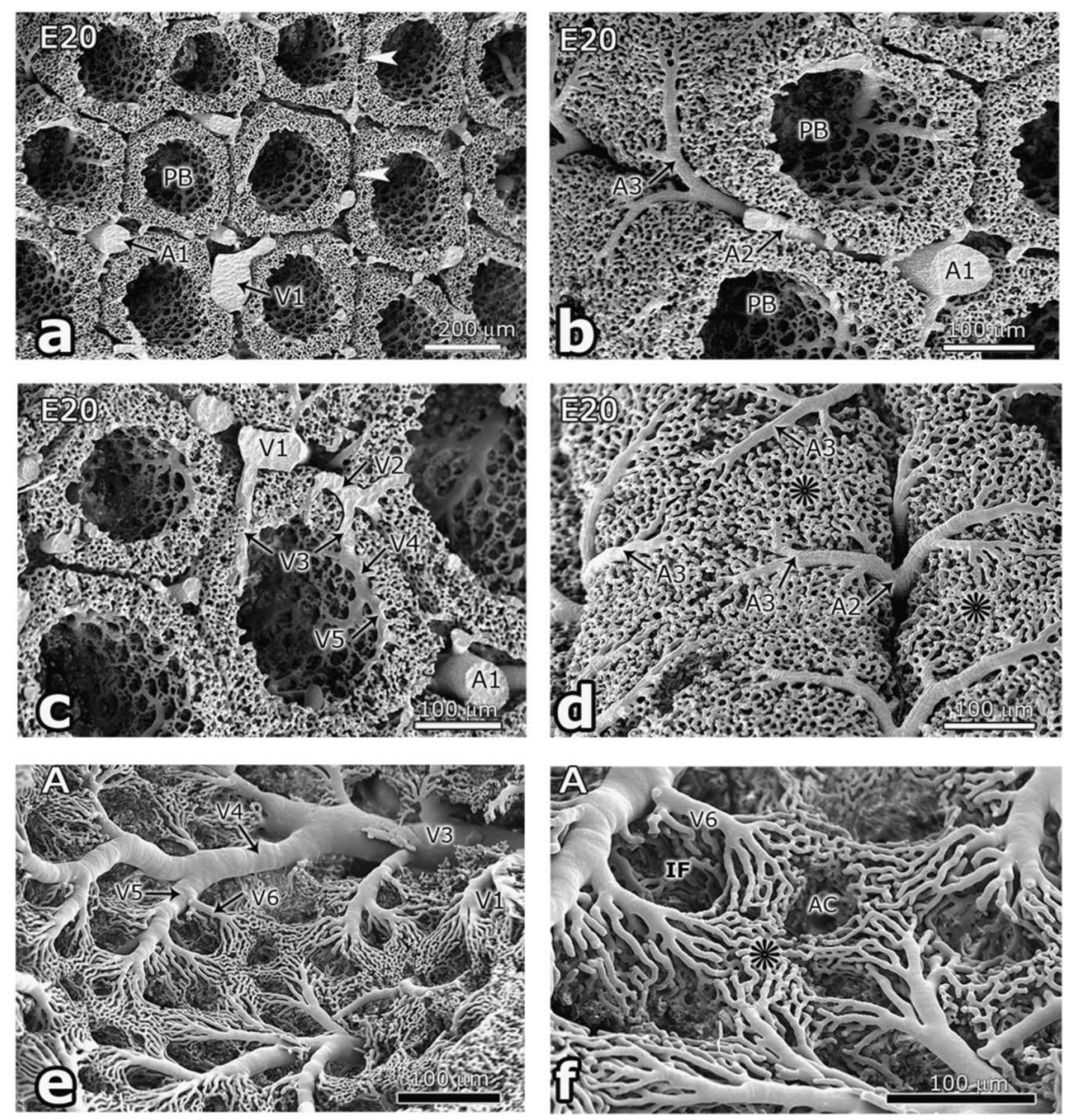

Figure 6. SEM micrographs from mercox vascular casts of the chicken lung showing the arrangement of the parabronchial (PB) vessels in the day 20 (E20) embryo (a-d) and in the adult (e, f). A: the capillary meshwork forms hexagonal tubes that surround the PB lumen. Adjacent $\mathrm{PB}$ are separated by the interparabronchial septum (arrowheads), which contains the interparabronchial artery (A1) and the interparabronchial vein (V1). b: A1 gives rise to parabronchial arteries (A2), which form parabronchial arterioles (A3) that break into a dense capillary meshwork. (c): V1 runs parallel to A1 and is joined by the parabronchial veins (V2), which receive intraparabronchial veins (V3). Atrial veins (V4), formed from convergence of septal venules (V5), drain into V3. D: on the external aspect of the capillary meshwork A3 branch from A2, and give rise to blood capillaries (asterisks) that surrounds the air capillaries (ACs). e, f: In the adult lung, infundibulae (IF) are surrounded by infundibular venules (V6), and join septal venules (V5) directly, which lead into atrial veins (V4). V4 drain into V3. Notice an individual AC surrounded by blood capillaries (asterisk). Reproduced with permission from Journal of Applied Physiology. 106, 1959-1969. Copyright @ 2009 the American Physiological Society. Scale bar: (a), $200 \mu \mathrm{m}$; (b-f), $100 \mu \mathrm{m}$.

(alcohols with multiple hydroxyl groups) used to make polyurethanes contain an average of two or more functional groups per molecule (Santerre et al., 2005). Polyurethanes remain one of the most popular group of biomaterials applied for medical devices due to their segmented block copolymeric character, which proffers them with a wide range of versatility in terms of tailoring their physical properties as well as blood and tissue compatibility (Santerre et al., 2005). In casting, PUs are versatile in that they can be used as pliable materials to cast specimens for dissection courses, as corroded casts for display, or even as casts for SEM (Figs. 7, 8). Indeed using polyurethane casting, it was demonstrated that glomerular recovery after Thy1.1 nephritis proceeded through intussusceptive angiogenesis (Wnuk et al., 2011, 2012), a novel mechanism of angiogenesis that is also involved in vascular patterning and angioadaptation (Makanya \& Djonov, 2009; Makanya et al., 2009). A combination of relative hardness and elasticity makes Pu4ii a superior casting agent compared with silicone (Meyer et al., 2007). Dissection of vessels injected with PU4ii proved easy and the vessels were palpable within the surrounding tissue, but nevertheless were elastic and tearresistant (Meyer et al., 2007).

Polyurethanes are suitable for a wide range of purposes, from macroscopic (Fig. 8) to ultrastructural investigations (Hlushchuk et al., 2008, 2011). By applying the Spalteholtz technique, arterial anastomoses can be demonstrated within tissues as described for the latissimus dorsi muscle (Meyer et al., 2007). The viscosity can be lowered by adding ethyl methyl ketone (EMK) or dimethylketone. Dilutions with 30\% EMK showed no significant changes in shrinkage behavior and other properties (Meyer et al., 2007). Polymerization times can be prolonged by using a slower hardener (Krucker et al., 2006; Meyer et al., 2007). The radio-opaque Iopamidol, a nonionic, low-osmolar iodinated contrast agent can be mixed with PU4ii 

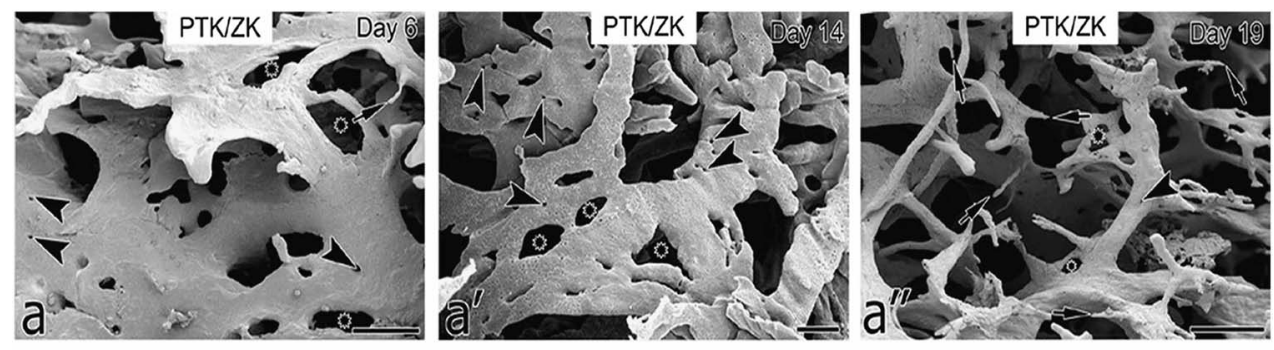
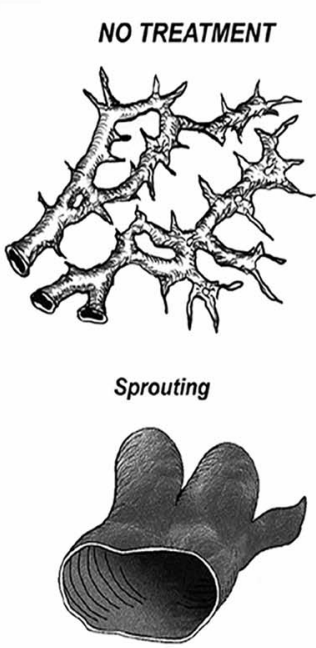

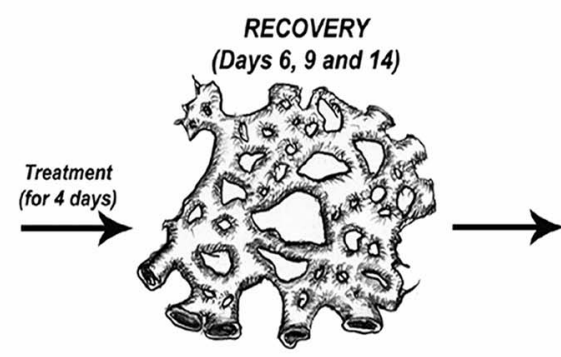

Intussusceptive phase

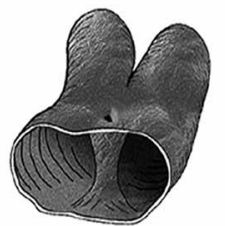

END OF RECOVERY
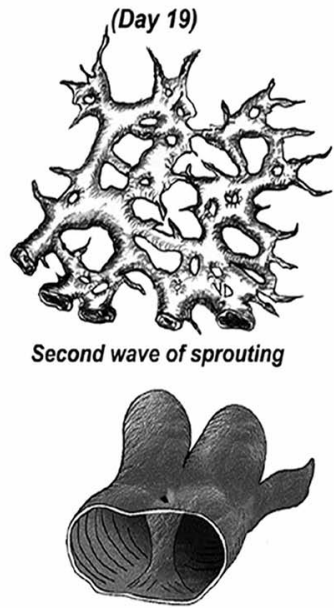

Figure 7. Time-course of the angiogenic switch from sprouting to intussusception during tumor recovery. a: Scanning electron micrographs representing the vascular pattern of the PTK/ZK treated tumors on day $6(\mathrm{a}), 14\left(\mathrm{a}^{\prime}\right)$ and $19\left(\mathrm{a}^{\prime \prime}\right)$. On day 6 and 14 pillars (arrowheads) and meshes (asterisks) dominate. In contrast to day 6 and 14, on day $19\left(\mathrm{a}^{\prime \prime}\right)$ the sprouts (arrows) prevail in the vascular pattern of the PTK/ZK-treated tumors with some pillars (arrowhead) or meshes (asterisks) present. The scheme in (B) represents the abovedescribed changes: in non-treated tumors the dominant mode of angiogenesis is sprouting. After the short-term therapy intussusception prevails: so called, intussusceptive phase of recovery (days 6, 9 and 14). On day 19 the second wave of intussusception occurs, what is characterized by numerous sprouts along with pillars or meshes. Adapted from Hlushchuk et al. (2011), reproduced with permission from The International Journal of Developmental Biology, 55, 2011, 563-567. Copyright (c) 2011 UBC Press. Scale bar is $100 \mu \mathrm{m}$.

for CT analyses (Twelves et al., 2012), although casts from PU4ii can be imaged using $\mu \mathrm{CT}$ without contrast agents to produce digital 3D reconstructions. Fluorescent colors can be added to PU4ii, which already possess inherent fluorescent properties, enabling the use of confocal microscopy (Meyer et al., 2008). Histological sections can be prepared from tissues in which blood vessels have been cast with PU4ii (Meyer et al., 2007), which gives the possibility that other techniques such immunostaining are feasible.

\section{Epoxy Resin Casting}

Epoxy resins (polyepoxides) are a class of reactive prepolymers and polymers, which contain epoxide groups. They may be cross-linked either with themselves through catalytic homopolymerization, or with a wide range of coreactants (hardeners). The hardeners include polyfunctional amines, acid phenols, alcohols, and thiols (Tanaka, 1988). The hardeners are often referred to as curatives, and the cross-linking reaction is commonly referred to as curing. Reaction of polyepoxides with themselves or with polyfunctional hardeners forms a thermosetting polymer, often with strong mechanical properties as well as high temperature and chemical resistance (Tanaka, 1988).
Epoxy resin (aradite) was used to study ischemia and neovascularization in the rat hind limb (Fig. 9) with the observation that collateral vessel formation and recanalization of previously thrombosed arteries occurred (Westerweel et al., 2005) to restore blood circulation in the limb. The latter authors combined epoxy resin casting with the Spalteholz technique, which entails dehydrating tissues in ascending concentrations of ethanol and clearing with methyl benzoate (Spalteholtz, 1914; Westerweel et al., 2005).

Biodur E20 is a translucent epoxy resin of medium viscosity, with firm, slightly flexible consistency. It was used for casting the arteries in the periodontium of horse teeth, some of which showed the quality required for SEM analysis. This was achieved by lowering the viscosity using MEK (Masset et al., 2006). The polymerization time for epoxy resins can be prolonged by lowering temperatures $\left(6-8^{\circ} \mathrm{C}\right)$ (Riepertinger \& Heuckendorf, 1993). The filling of the arteries supplying delicately soft tissue such as the brain or casting the brain ventricular system is usually preceded by stabilizing the tissue with chemical fixatives (Aultman et al., 2003). Stabilization of the brain in situ before casting with Biodur E20 was achieved with 10\% formalin fixation for about $3 \mathrm{~h}$ before injection with the epoxy resin. The brain 

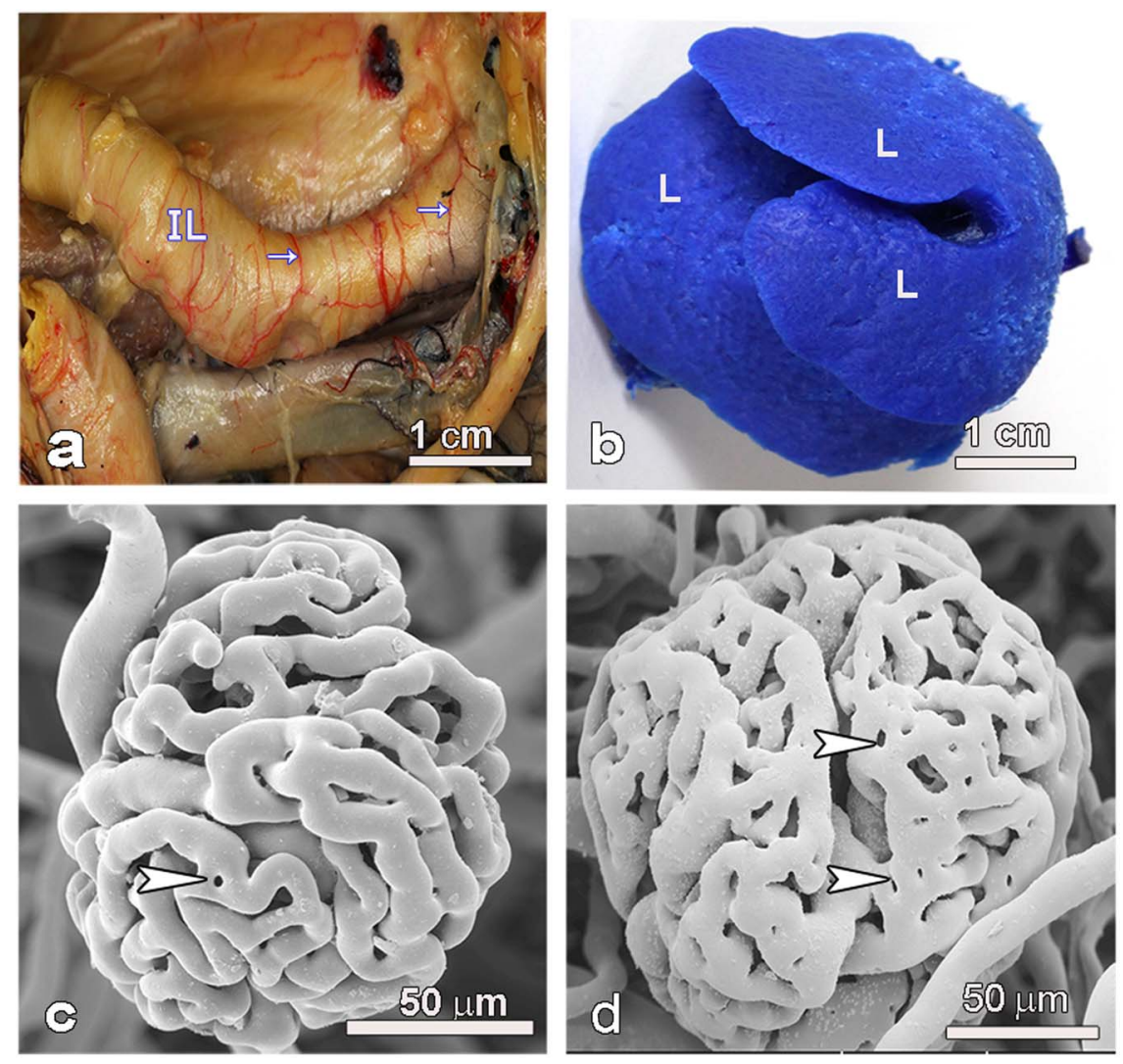

Figure 8. Photographs showing the various applications of polyurethane. a: Pu4ii mixed with red dye to show vasa vasorum (arrowheads) in the human iliac artery. $\mathbf{b}$ : Pu4ii mixed with blue dye to cast a mouse liver. $\mathbf{c}$, d: SEM micrographs of polyurethane casts showing a normal glomerulus (c) and one that is recovering from Thy1.1 nephritis (d). Note that restitution of blood vessels in this case proceeds through intraluminal pillar formation (arrowheads). NB: a-d: are unpublished data kindly donated by colleagues Hannes Bangerter and Monica Wnuk. Scale bar: (a, b), $1 \mathrm{~cm}$; (c, d) $50 \mu \mathrm{m}$.

specimen was subsequently plastinated for use by medical students (Riepertinger \& Heuckendorf, 1993).

\section{Polyester Resin Casting}

The polyester resins used in casting are unsaturated resins formed by the reaction of dibasic organic acids and polyhydric alcohols. Water, a by-product of esterification reactions, is continuously removed driving the reaction to completion. The use of unsaturated polyesters and additives such as styrene lowers the viscosity of the resin. The initially liquid resin is converted to a solid by crosslinking chains (Stamatakis et al., 2010). Creation of free radicals at the unsaturated bonds propagates a chain reaction to other unsaturated bonds in adjacent molecules, linking them in the process. To reduce working temperatures (called cold-setting) and thus hasten the hardening process a catalyst is used (John et al., 2008). Three percent methyl ethyl peroxide (Pereira-Sampaio et al., 2012) or styrene monomer (John et al., 2008) are popular catalysts. Polyester forms a brittle nonpliable cast, is capillarypassable, can be used for SEM (Ohkuma et al., 1997), and is also used as a plastination resin (Weiglein, 1997). Excessive catalyst may also cause the product to fracture or form a rubbery material.

\section{General Procedures for Producing CASTS}

The general procedures for producing good casts are similar for all materials and purposes. Three main steps, which might differ in the amount of effort and time required are recognized. These include the preparatory process, injection, and the postprocessing work. Handling of the casting materials, particularly, the toxic solvents and catalysts requires strict adherence to instructions and safety precautions. For all materials the procedures and attendant precautions are normally provided by the manufacturers and are included in the consumer brochures.

\section{Precasting Procedures}

Preparatory work includes the handling of the biological specimen selected for casting and the preparation of the casting material. The success of the cast also depends on the biological specimen involved, such as its age (Sanan et al., 1999) and condition. In general, wherever possible, it is advisable to use fresh tissues to circumvent problems, such as rigor mortis, postmortem degradation of the vascular system, or pressure sores (Bergeron et al., 2006). Nevertheless, cattle feet stored for $2-3$ weeks at $4^{\circ} \mathrm{C}$ revealed better filling at 

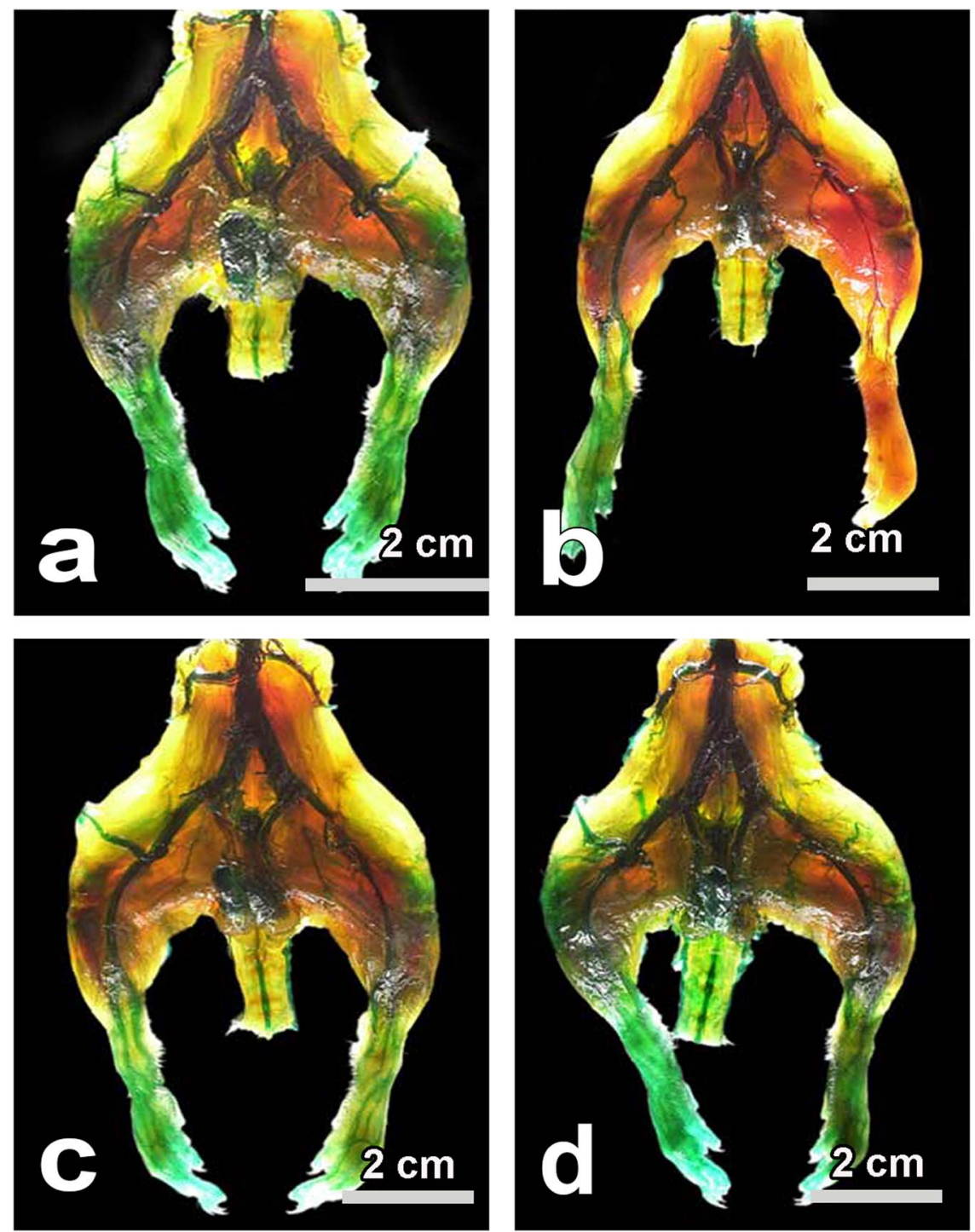

Figure 9. Series of araldite preparations photographed from the ventral side, made in a control rat (a) and after induction of ischemia by ligation of the left femoral artery. Seven days after ligation (b), there is profound ischemia on the ligated side, and distal arteries are thrombosed. After 14 days (c), collaterals have formed and flow is restored in the original conduit arteries. Total recovery has taken place after 21 days (d). Modified from Westerweel et al. (2005), reproduced with permission from Cardiovascular Pathology, 14, $294-297$. Copyright (c) 2011 Elsevier Limited. Scale bar is $2 \mathrm{~cm}$.

the microvascular level when compared with fresh specimens. It appears that the time lag had resolved postmorten blockages without disrupting the vessels as confirmed by SEM (Hirschberg et al., 1999).

Generally, prior embalming results in tissue fortification allowing easy handling and ample time for casting, especially for Thiel embalming (Graz method) where specimens are preserved in near natural color, strength and pliability (Jaung et al., 2011). Such specimens are particularly suitable for surgical courses, as specimens remain soft and flexible and the colors resemble those of real patients (Jaung et al., 2011; Thiel, 1992a). Latex and silicone rubbers can also be applied in formalin-embalmed specimens as demonstrated for facial arteries (Magden et al., 2004; Pinar et al., 2005). The arteries supplying isolated brains were demonstrated with latex casting, subsequently immersion-fixed in $10 \%$ formalin
(Sen et al., 2011). Latex hardens quickly in the presence of formaldehyde (Bergeron et al., 2006), ethanol and diluted acids (Mulisch \& Welsch, 2010). Pu4ii casting can also easily be applied to formalin-embalmed specimens (Meyer et al., 2007).

\section{Dissection and Irrigation}

Where small components of a specimen are targeted, dissection may be required to reveal the supplying vessels for injection (Alvernia et al., 2010) or where specific organs such as the kidney need to be isolated for individual casting. Irrigation of the vasculature of fresh specimens is done with phosphate buffered saline, preferably mixed with an anticoagulant such as heparin to prevent blood from clotting (Makanya et al., 2007). In fixed specimens, irrigation with 
tap water is done to remove blood clots and tissue debris and also to reveal the anatomical variants of the arterial and venous systems (Alvernia et al., 2010). Depending on the type of specimen under investigation, it may be necessary to irrigate the arterial and venous systems separately. In the latter circumstance, the arterial system is irrigated before the venous system because venous congestion may lead to increased resistance and decreased arterial flow (Alvernia et al., 2010). Filling of the targeted body cavities for casting may require the insertion of cannulas. Different kinds of cannulas can be used (Sanan et al., 1999), for example Foley catheters, which allow the inflation of a balloon to close the vessels following injection (Alvernia et al., 2010).

Irrigation of vessels is subject to controversy as previously noted (Grabherr et al., 2007). Some authors describe it as an essential step to remove blood clots and possible remains of embalming fluid (Sanan et al., 1999). Others achieved their best casts from nonrinsed specimens. For example, rinsed cattle feet prepared for casting with Mercox or Tensolcement revealed more filling defects when compared with nonrinsed feet (Hirschberg et al., 1999). A possible explanation might be that the perfusion solution provided additional blockage finally preventing capillary filling (Hirschberg et al., 1999). Nevertheless, one advantage of irrigation is the detection of leaks (Shimizu et al., 2006) and the opening of possible anastomoses (Alvernia et al., 2010). Pre-fixation of tissue is recommended for brains to provide organ stability (Riepertinger \& Heuckendorf, 1993; Aultman et al., 2003; Alvernia et al., 2010) and to improve vascular properties before casting the microvasculature (Verli et al., 2007). For small specimens with delicate blood vessels such as those of the area vasculosa, irrigation or even canulation may not be feasible and the resin is injected directly (Dimova et al., 2013). In the latter situation it is mandatory that the vascular system is opened at an appropriate point to allow escape of the displaced blood.

\section{Evacuation}

In plastination, evacuation refers to removal of vaporized acetone from tissues to allow infiltration with the desired polymer resin, a process conducted in vacuo (Ravi \& Bhat, 2011). In casting, evacuation may refer to removal of air from the casting medium or from the specimen to be casted. In the former case, the process of evacuation is an important step and aims to remove any trapped inclusions of air from the mixture as air bubbles might result in incomplete casts prone to fracture (Leiser \& Pfarrer, 2005). Short polymerization times might prevent this as seen with Technovit 7143 (Cordes, 1989). Evacuation may also refer to expulsion of air particularly from blind ending cavities such as the tracheobronchial system of lungs (Jacob et al., 2013). This is achieved either by removing lungs from the thoracic cavity (Cope, 2008) or inducing a pneumothorax by puncturing the diaphragm, or by making an opening in the thoracic cage (Maina \& van Gils, 2001; Makanya et al., 2001).

\section{Injection and Infusion Procedures}

In general, injection and infusion pressures need to be carefully adapted to prevent either incomplete filling or rupture of structures (Verli et al., 2007). Overfilling of the arterial systems might result in leakage of casting material into the venous system (Bergeron et al., 2006). Many authors describe the manual injection of casting material but the use of an injection apparatus has advantages as it keeps a constant injection pressure and can help to prevent the introduction of air bubbles (Minnich \& Lametschwandtner, 2010). There are several signs that mark the end of the injection process, such as the outflow of capillary-passable casting materials from the venous side (Pollitt \& Molyneux, 1990; Leiser \& Pfarrer, 2005; Alvernia et al., 2010). Outflow from contralateral arteries (Sanan et al., 1999) or opposite ends of ducts as well as casting material that shines through the skin (Vandeghinste et al., 2011) are positive signs, which are often preceded by an increase of pressure within the syringe (Latorre et al., 2001). The complete emptying of the syringe is not recommended as it might introduce air bubbles (Cordes, 1989). Tissue damage from pressure points can be avoided by injecting the casting material while the specimen or organ is floating (Cordes, 1989) or by transferring it into a water tank immediately following injection (Bergeron et al., 2006). To fill more than one artery such as the simultaneous injection of the four main arteries of the brain can be realized by using a four-way injection system (Riepertinger \& Heuckendorf, 1993). In partially blocked tubular systems, application of a negative pressure helps infusion of the casting material. Perry et al. (2000) used $10 \mathrm{kPa}$ negative pressure generated in a vacuum chamber to force silicone rubber thinned with silicone oil into lung tissue with partially blocked airways.

\section{Postcasting Procedures}

The procedures immediately subsequent to casting depend on the targeted final product. For specimens intended for anatomical and surgical procedures, further dissection may be necessary. Tissue clearing is done making the specimen transparent if the casted internal structures are intended for display in situ (Spalteholtz, 1914; Walter et al., 2012). Corrosion of surrounding tissue is undertaken if clean casts devoid of any tissue are required and in addition sputtercoating with metals or metal complexes is done if specimens are intended for observation with a SEM (De Sousa Bolina et al., 2013). It is essential to await the complete polymerization of the casting material, which ranges from hours to days and which is dependent on the diluting agents used.

\section{Dissection}

Many researchers and surgeons appreciate the advantages of filled and colored vessels as they facilitate dissection and identification of vessels, their course and branches, and the determination of vessel diameters (Perry et al., 2000; Magden et al., 2004; Kappler et al., 2005; Pinar et al., 2005; Coquerel-Beghin et al., 2006). Dissection may be done post 
casting either to remove undesirable tissue such as fat or to reveal targeted structures such as blood vessels (Gao et al., 2013).

\section{Tissue Clearing}

A 3D visualization of the vascular network within organs is possible by applying a technique that makes the organ translucent, such as achieved with the method according to Spalteholz (Tilotta et al., 2009). It is noteworthy that the method is time-consuming and only applicable on small specimens and, of course, is most effective with filled vessels (Bergeron et al., 2006). Modified methods of Spalteholtz were shown to enhance visualization of silicone rubber-filled vascular networks in muscles (Kappler et al., 2005) and PU4ii-filled arterial anastomoses within parts of the latissimus dorsi muscle (Meyer et al., 2007). Clearing agents include glycerin (An et al., 2012), solution of benzyl alcohol, benzyl benzoate (Walter et al., 2012), or methyl benzoate (Westerweel et al., 2005). One negative aspect, possibly resulting from the clearing process, might be the swelling of vessels as observed by Meyer et al. (2007).

\section{Corrosion}

The removal of soft tissue post casting can be biological or can employ chemical methods. In nonfixed/nonpreserved tissue, the natural processes of autolysis and putrefaction, which utilize endogenous and microbial enzymes, respectively, ultimately result in tissue destruction (Culling, 1974). This process can take a long time and is aesthetically undesirable. Use of carrion insects (Braack \& de Vos, 1987) is more elegant since such are easier to control.

The choice of corrosive agents depends on the purpose of the cast and on the properties of the tissue. Preservation of delicate structures requires mild methods of maceration, such as enzymatic maceration, long-term natural decay of organic material or the use of biological methods (Cordes, 1989). For example, the larvae of necrophagous hide beetles (Dermestes maculatus) were used to clear the soft tissue from silicone rubber-filled nasolacrimal ducts of cats as well as the nasal cavity (Nöller et al., 2006). In a duck lung specimen casted with silicone rubber and stored for the rubber to cure, we found hordes of maggots from houseflies (Musca domestica) devouring the soft tissues 3 days later and let them complete the process. A time-consuming (about 6 months) but effective method is the use of common detergent at $60^{\circ} \mathrm{C}$ (Masset et al., 2006). Fresh biological material can be boiled in water for several hours, which macerates the soft tissue as was demonstrated in silicone rubber-filled lungs and airways (Henry, 1992). Other methods include the use of chemicals such as strong alkalis, Ariel, or enzymes such as pancreatin or papain (Pulvertaft, 1950). Different dilutions of potassium hydroxide $(\mathrm{KOH})$ have been used for a wide range of specimens and for various durations as the following examples show: $\mathrm{KOH}(20 \%)$ at $40^{\circ} \mathrm{C}$ for $12 \mathrm{~h}$ applied on Technovit 7143 and Mercox-filled vessels (Waldmann, 2006); $40 \% \mathrm{KOH}$ at $30^{\circ} \mathrm{C}$ for 1 day applied on
Technovit 7143-filled ovine livers (Cordes, 1989); 7.5\% KOH at $50^{\circ} \mathrm{C}$ for $24 \mathrm{~h}$ applied on Pu4ii-filled mouse arteries (Krucker et al., 2006). Other investigators (Hossler et al., 2013) used $5 \% \mathrm{KOH}$ at $60^{\circ} \mathrm{C}$ overnight showing that at higher temperatures, a lower concentration of the corroding reagent is feasible. The duration of the corrosion process depends on how tough and big the soft tissue is and may require up to 4 weeks.

\section{SEM}

Casts intended for use in SEM need to be processed according to the general procedures stipulated for SEM (Worthen \& Wickham, 1972; Verli et al., 2007). Bony structures, for example can be decalcified using formic acid to reveal the casts for further processing (Krucker et al., 2006). Further steps comprise dehydration, drying and mounting of the specimen on a conductive surface and sputter coating with a suitable metal or metal alloy such as chromium, gold or palladium, and finally adjusting the acceleration voltage during microscopy (Verli et al., 2007). The application of $\mu \mathrm{CT}$ requires the immersion of the specimens in osmium as demonstrated for PU4ii (Meyer et al., 2007) or Batson No.17 (Vandeghinste et al., 2011). Morphometric techniques such as estimation of vascular density (Makanya et al., 2007) or branching angles (Ackermann et al., 2013) can be determined from casts imaged by SEM.

\section{Plastination and Polyethylene Glycol (PEG) Impregnation}

Some casting materials are of limited suitability for plastination, such as seen with gelatin that produces cracks (Grondin et al., 2000) and latex that can swell in methylene chloride (Henry et al., 1997). For application of plastination as a postcasting procedure, epoxy resins such as Biodur E20 and silicone rubbers, such as Biodur S14 are recommended. It is advisable to test the colors beforehand (Pereira-Sampaio et al., 2011). Silicone rubber casting is compatible with subsequent PEG impregnation (Bertagnoli et al., 2012).

\section{Methods for Modifications of Casting Procedures}

The modifications most often applied affect viscosity and the time required for polymerization. The viscosity of a casting material refers to its fluidity, whether it is thick (high viscosity) or thin (low viscosity), and hence determines its flow through the varying diameters of structures. Polymerization time, sometimes referred to as pot life, determines the time left from mixing the components, including any additives and hardener (catalyst), until the mixture starts to cure. Viscosity needs to be modified in the uncured state and, in turn, affects the time needed for polymerization. Common diluting agents and other means of influencing viscosity and polymerization times are provided below. 


\section{Gelatin}

Gelatin requires warm conditions to maintain viscosity at a level appropriate for injection, around $40^{\circ} \mathrm{C}$ but not higher than $50^{\circ} \mathrm{C}$ (Bergeron et al., 2006). Lower temperatures cause it to solidify but the process is reversible. The protein content affects setting times. Gelatin quickly hardens in the presence of formaldehyde (Tompsett, 1970; Bergeron et al., 2006).

\section{Latex}

Latex can be diluted with water (Alvernia et al., 2010), ammonium hydroxide or triethylamine. The addition of diluting agents results in longer postinjection setting periods (Alvernia et al., 2010). Formalin, ethanol, and diluted acid solutions cause latex to solidify (Mulisch \& Welsch, 2010).

\section{Silicone Rubbers}

Silicone oils (polydimethylsiloxane) are used to dilute silicon rubber (Perry et al., 2000; Makanya \& Djonov, 2008) but thinner solutions are also used (Sanan et al., 1999). The ratio (silicone rubber: thinner) should be adapted to the type of vessel involved. Sanan et al. (1999) recommend a less viscous mixture for the arterial system due to the greater resistance and mixed 1:1 for arteries and 2:1 for veins, but a wide range of ratios has been used by others (Shimizu et al., 2006). Adjusting the dosage of hardener usually alters polymerization times (Kaya et al., 2006).

\section{Methacrylates}

Technovit 7143 can be diluted by varying the ratio of powder to liquid or by adding monomer methyl methacrylate (MMA), which acts as a diluent (Hirschberg et al., 1999) or acetone (Cordes, 1989). Polymerization times can be prolonged by modifying the ratio of powder to liquid or by storing it in a refrigerator $\left(6-8^{\circ} \mathrm{C}\right)$ (Hirschberg et al., 1999), although Waldmann (2006) observed only slight improvement with injection of Technovit 7143 into ice-cooled specimens.

Tensolcement can be diluted with ethyl acetate (Hirschberg et al., 1999) while Mercox (Hirschberg et al., 1999) and Batson No.17 (Pollitt \& Molyneux, 1990) are diluted with the monomer, MMA. Polymerization durations for Tensolcement and Mercox can be prolonged by lowering temperatures $\left(6-8^{\circ} \mathrm{C}\right)$ (Hirschberg et al., 1999). Polymerization of Batson No.17 begins within 3-5 min of mixing with the hardener and thus requires quick injection (Leiser \& Pfarrer, 2005), cooling down $\left(4^{\circ} \mathrm{C}\right)$ delays the process (Leiser \& Pfarrer, 2005). Reducing the amount of accelerator in the latter case prolongs the polymerization process (Pollitt \& Molyneux, 1990). The addition of diluent acetone causes Technovit 7143 to become brittle and to trap more air bubbles (Cordes, 1989).

\section{Polyurethanes (PU4ii)}

Polymerization times can be prolonged by using a slower hardener (Krucker et al., 2006) and viscosity can be lowered with EMK or dimethylketone (Meyer et al., 2007). Any modification of viscosity comes at the expense of other desired properties, such as curing times. Meyer et al. (2007) diluted PU4ii with maximal $30 \%$ MEK without noticing significant changes in shrinkage behavior and other properties, but as noted elsewhere, shrinkage is a well-known problem associated with dilution (Verli et al., 2007).

\section{Coloration}

Desired modifications of properties comprise coloration as it facilitates visualization and can make a difference in distinguishing tissues. Red-colored Microfil, for example, can be better seen in translucent brain tissue while yellowcolored Microfil is better visible in translucent myocardium (Walker et al., 2011). Possible color inducing agents include colored dyes, pigments, and color pastes and in principle it is possible to apply any color that mixes well with the casting material (Nöller et al., 2006; Shimizu et al., 2006). Latex is available in different colors, but its color can be altered by adding poster paint or pigment paste (Latorre et al., 2001). Here, caution is advised as the application of alternative colors might interfere with postprocessing steps, such as plastination. Addition of pigmented colors to silicone rubber resulted in a loss of color intensity during treatment in an acetone bath (Pereira-Sampaio et al., 2011) and in latex-filled structures of plastinated equine forelimbs (Latorre et al., 2001). A possible explanation is that the pigment used was not color-stable (Latorre et al., 2001). The colored pigments should be mixed with the diluent, if possible, before adding it to the casting material as recommended for silicone rubber (Smith \& Rhoton, 1999). Fluorescent agents can be added to PU4ii, which already possess inherent fluorescent properties, enabling the use of confocal microscopy (Meyer et al., 2007). Whitening of casts can be achieved by treatment with $10 \%$ hydrogen peroxide as demonstrated for canine silicon tracheobronchial casts (Cope, 2008).

\section{Unusual Casting Media and Methods}

\section{India Ink and Gelatin}

India ink may be combined with gelatin (Kolts et al., 1994; Ninomiya et al., 2011). This can be achieved by mixing $300 \mathrm{~mL}$ of $5 \%$ gelatin and $0.5 \%(\mathrm{v} / \mathrm{v})$ India ink solution and injecting into arteries (Kolts et al., 1994).

\section{Lead Oxide and Milk Mixture}

A mixture of lead oxide and milk was used to demonstrate the arterial supply of the long head of biceps brachii tendon in human cadavers (Cheng et al., 2010). This unusual combination had previously been demonstrated to deliver consistently high-quality radiographs largely at par with those from fresh cadavers (An et al., 2012). Prior to injection with lead oxide, the upper limb specimens were injected with $50 \mathrm{~mL}$ of $6 \%$ hydrogen peroxide via the axillary artery and then submerged in a warm water bath at $\sim 50{ }^{\circ} \mathrm{C}$ for $3 \mathrm{~h}$. Preferably, injections are performed in a pulsatile fashion, with the plunger being rhythmically pushed and released by 
hand to mimic the normal heartbeat. This technique decreased the risk of vessel rupture (Rees \& Taylor, 1986).

\section{Casting Combined with Plastination}

Casting may be combined together with plastination to improve quality and fortitude of a specimen. Casting of the vitreous chamber of the porcine eye was achieved with silicone S10 followed by plastination of the wall of the eyeball (bulbus oculi) with PEG (Sivrev et al., 1997). The combination of two chemically different polymers resulted in soft and life-like eyes, safe for student handling and use during anatomical study and also for practicing delicate surgical procedures (Sivrev et al., 1997).

\section{Casting Combined with Histology}

Small fragments of tissue injected with PU4ii may be processed by fixation in $2.5 \%$ glutaraldehyde, dehydration in ascending concentrations of ethanol and embedded in paraffin wax (Meyer et al., 2007). Sections of $8-10 \mu \mathrm{m}$ were stained with Haemalaun-Eosin and van Gieson and evaluated for the presence of PU4ii in small vessels (Meyer et al., 2007). PU4ii casting has also been combined with fluorescence microscopy to view thioflavin S-labeled Alzheimer plaques in PU4ii casted brain tissue. Inherent fluorescence of the casting material allows visualizing the relation of the vasculature and plaques simultaneously (Meyer et al., 2008).

\section{Vinyl Acetate Casting}

Vinyl acetate is an organic compound with the formula $\mathrm{CH}_{3} \mathrm{COOCH}=\mathrm{CH}_{2}$. A colorless liquid with a pungent odor, it is the precursor to polyvinyl acetate. It can be polymerized, either by itself to make polyvinyl acetate, or with other monomers to prepare copolymers such as ethylene-vinyl acetate. About $80-100 \mathrm{~mL}$ of solution prepared with $30 \%$ acetone colored with red nitrocellulose lacquer was injected into femoral arteries of seven human cadaver specimens (three right side and four left side) (Tanaka et al., 2006). The portion with the femoral artery was dissected out. Specimens were kept without traction, at $15^{\circ} \mathrm{C}$, for a period of 3 days and afterwards taken to corrosion in a $30 \%$ sulfuric acid solution for 10 days. After this period, the solution was substituted with a $50 \%$ sulfuric acid solution, for another 10 days, after which the specimens were carefully washed in water for $4-5 \mathrm{~h}$ (Tanaka et al., 2006).

\section{CONCLUSION}

The literature describing casting methods, materials and their uses is vast and progressive. The production of successful casts depends on a number of factors. It starts with the choice of the biological specimen and the appropriate casting material without losing focus of the targeted use and application of the cast. Moreover, those studies pointing out the advantages and disadvantages and/or failure rates are very useful but the number of such studies is quite limited. It is important to point out that the specimens to be injected comprise biological material, which often makes the outcome unpredictable. It is common that many attempts may be required before obtaining usable casts. The importance of casts in teaching and research cannot be overemphasized. While computer-based learning resources have a complementary role to traditional learning methods, they appear to have significant disadvantages compared to traditional use of specimens in learning nominal anatomy (Khot et al., 2013). Virtual reality shows no advantage over static presentation of key views (Khot et al., 2013) and physical models have a significant advantage over alternative learning resources in enhancing understanding of complex 3D anatomical architecture (Preece et al., 2013). Furthermore, discoveries of novel biological processes such as intussusceptive angiogenesis were achieved through casting (Caduff et al., 1986; Makanya et al., 2009).

\section{ACKNOWLEDGEMENTS}

We thank Barbara Krieger for technical assistance. Figure 8 was a kind donation from colleagues Hannes Bangerter and Monica Wnuk. This work was supported by Swiss National Science Foundation grant No. 31003A_1357408.

\section{RefERENCES}

Ackermann, M., Tsuda, A., Secomb, T.W., Mentzer, S.J. \& Konerding, M.A. (2013). Intussusceptive remodeling of vascular branch angles in chemically-induced murine colitis. Microvasc Res, 87, 75-82.

Aharinejad, S.H. \& Lametschwandtner, A. (1992). Corrosion casting-a historical review. In Microvascular Corrosion Casting in Scanning Electron Microscopy, Aharinejad, S.H. \& Lametschwandtner, A. (Eds.), pp. 3-11. Vienna: Springer-Verlag.

Akester, A.R. (1960). The comparative anatomy of the respiratory pathways in the domestic fowl (Gallus domesticus), pigeon (Columbia livia) and domestic duck (Anas platyrhynchos). J Anat, 94, 487-505.

Alvernia, J.E., Pradilla, G., Mertens, P., Lanzino, G. \& Tamargo, R.J. (2010). Latex injection of cadaver heads: Technical note. Neurosurgery, 67, 362-367.

An, X., Yue, B., Lee, J.H., Lin, C. \& Han, S.H. (2012). Arterial anatomy of the gracilis muscle as determined by latex injection and glycerin transparency. Clin Anat, 25, 231-234.

Aultman, A., Blythe, A.J., Sowder, H., Trotter, R. \& Raoof, A. (2003). Enhancing the value of organ silicone casts in human gross anatomy education. J Int Soc Plastination, 18, 9-13.

Benzioni, H., Shahar, R., Yudelevich, S., Shipov, A. \& Milgram, J. (2009). Lateral thoracic artery axial pattern flap in cats. Vet Surg, 38, 112-116.

Bergeron, L., TANG, M. \& Morris, S.F. (2006). A review of vascular injection techniques for the study of perforator flaps. Plast Reconstr Surg, 117, 2050-2057.

Berrie, B.H. (1997). Prussian Blue. In Artists' Pigments: A Handbook of their History and Characteristics, Fitzhugh, E.W. (Ed.), pp. 191-218. Washington, DC: National Gallery of Art.

Bertagnoli, A., RÄber, M., Morandi, N., Mortellaro, C.M. \& Steiner, A. (2012). Tenovaginoscopic approach to the common digital flexor tendon sheath of adult cattle: Technique, normal findings and preliminary results in four clinical cases. Vet J, 191, 121-127. 
Bickley, H.C., von Hagens, G. \& Townsend, F.M. (1981). An improved method for the preservation of teaching specimens. Arch Pathol Lab Med, 105, 674-676.

Bickley, H.C., Walker, A.N., JACKSON, R.L. \& Donner, R.S. (1987). Preservation of pathology specimens by silicone plastination. An innovative adjunct to pathology education. Am J Clin Pathol, 88, 220-223.

Bidloo, G. (1685). Anatomia Humani Corporis. Amsterdam: Someren, Dyk, Hendrick \& Boom.

Boyd, A.S., Benjamin, H.J. \& Asplund, C. (2009a). Principles of casting and splinting. Am Fam Physician, 79, 16-22.

Boyd, A.S., Benjamin, H.J. \& Asplund, C. (2009b). Splints and casts: Indications and methods. Am Fam Physician, 80, 491-499.

BrAaCK, L.E. \& DE VOS, V. (1987). Seasonal abundance of carrion-frequenting blow-flies (Diptera: Calliphoridae) in the Kruger National Park. Onderstepoort J Vet Res, 54, 591-597.

Breit, S., Kunzel, W. \& Oppel, M. (2003). The course of the nasolacrimal duct in brachycephalic cats. Anat Histol Embryol, 32, 224-227.

Caduff, J.H., Fischer, L.C. \& Burri, P.H. (1986). Scanning electron microscope study of the developing microvasculature in the postnatal rat lung. Anat Rec, 216, 154-164.

Cheng, N.M., Pan, W.R., Vally, F., Le Roux, C.M. \& Richardson, M.D. (2010). The arterial supply of the long head of biceps tendon: Anatomical study with implications for tendon rupture. Clin Anat, 23, 683-692.

Chern, C.S. (2006). Emulsion polymerization mechanisms and kinetics. Prog Polym Sci, 31, 443-486.

Cooke, R. (2010). A moulage museum is not just a museum. Virchows Arch, 457, 513-520.

Cope, L.A. (2008). Tracheobronchial cast production and use in an undergraduate human anatomy course. Anat Sci Educ, 1, 23-26.

Coquerel-Beghin, D., Milliez, P.Y., Auquit-Auckbur, I., Lemierre, G. \& Duparc, F. (2006). The gracilis musculocutaneous flap: Vascular supply of the muscle and skin components. Surg Radiol Anat, 28, 588-595.

CoRdEs, J. (1989). Korrosionstechnik. Der Präparator, 35, 21-28.

Culling, C.F.A. (1974). Handbook of Histopathological and Histochemical Techniques (Including Museum Techniques). London: Butterworths.

De Sousa Bolina, C., De Sousa Bolina-Matos, R., De Matos Alves, P.H., Pulzato Cury, D., Ciena, A.P. \& Watanabe, I.-S. (2013). Three-dimensional aspects of the structural characteristics and kidney angioarchitecture of adult and aged wistar rats: A scanning electron microscopy study. Microsc Res Tech, 76, 538-544.

Dimova, I., Hlushchuk, R., MaKanya, A., Styp-Rekowska, B., Ceausu, A., Flueckiger, S., Lang, S., Semela, D., Le Noble, F., Chatterjee, S. \& Djonov, V. (2013). Inhibition of Notch signaling induces extensive intussusceptive neo-angiogenesis by recruitment of mononuclear cells. Angiogenesis, 16, 921-937.

Fujimoto, M., Suzuki, H., Shiba, M., Shimojo, N., ImanaKa-Yoshida, K., Yoshida, T., Kanamaru, K., Matsushima, S. \& Taki, W. (2013). Tenascin-C induces prolonged constriction of cerebral arteries in rats. Neurobiol Dis, 55, 104-109.

GaO, L., Wang, L., Su, B., Wang, P., Ye, J. \& Shen, H. (2013). The vascular supply to the spinal cord and its relationship to anterior spine surgical approaches. Spine J, 13, 966-973.
Geurtsen, W. (2002). Biocompatibility of dental casting alloys. Crit Rev Oral Biol Med, 13, 71-84.

Goodwin, M.B. \& Chaney, D.S. (1994). Molding and casting: techniques and materials. In Vertebrate Paleontological Techniques, Leiggi, P. \& May, P. (Eds.), pp. 235-271. New York: Cambridge University Press.

Grabherr, S., Djonov, V., Yen, K., Thali, M.J. \& Dirnhofer, R. (2007). Postmortem angiography: Review of former and current methods. AJR Am J Roentgenol, 188, 832-838.

Grondin, G. (2005). Uses and abuses of the word 'plastination'. J Int Soc Plastination, 20, 4-5.

Grondin, G., Sianothai, A. \& Olry, R. (2000). In situ ventricular casts of S10 plastinated human brains. J Int Soc Plastination, 15, $18-21$.

Groscurth, P., Eggli, P., Kapfhammer, J., Rager, G., Hornung, J.P. \& FASEL, J.D.H. (2001). Gross anatomy in the surgical curriculum in Switzerland: Improved cadaver preservation, anatomical models, and course development. Anat Rec, 265, 254-256.

Henry, R.W. (1992). Silicone tracheobronchial casts. J Int Soc Plastination, 6, 38-40.

Henry, R.W., Daniel, G.B. \& Reed, R.B. (1998). Silicone casting of the chambers of the heart and the great vessels. J Int Soc Plastination, 13, 17-19.

Henry, R.W., Janick, L. \& Henry, C. (1997). Specimen preparation for silicone plastination. J Int Soc Plastination, 12, 13-17.

Hermiz, D.J., O'Sullivan, D.J., Lujan, H.L. \& DiCarlo, S.E. (2011). Constructivist learning of anatomy: Gaining knowledge by creating anatomical casts. Anat Sci Educ, 4, 98-104.

Heymans, O.Y., Nelissen, X.P., Peters, S., Lemaire, V. \& Carlier, A. (2004). New approach to vascular injection in fresh cadaver dissection. J Reconstr Microsurg, 20, 311-315.

Hirschberg, R.M., Mulling, C.K. \& Bragulla, H. (1999). Microvasculature of the bovine claw demonstrated by improved micro-corrosion-casting technique. Microsc Res Tech, 45, 184-197.

Hlushchuk, R., Makanya, A.N. \& Djonov, V. (2011). Escape mechanisms after antiangiogenic treatment, or why are the tumors growing again? Int J Dev Biol, 55, 563-567.

Hlushchuk, R., Riesterer, O., Baum, O., Wood, J., Gruber, G., Pruschy, M. \& Djonov, V. (2008). Tumor recovery by angiogenic switch from sprouting to intussusceptive angiogenesis after treatment with PTK787/ZK222584 or ionizing radiation. Am J Pathol, 173, 1173-1185.

Hodde, K.C. \& Nowell, J.A. (1980). SEM of micro-corrosion casts. Scan Electron Microsc, 89-106.

Hossler, F.E. \& Douglas, J.E. (2001). Vascular corrosion casting: Review of advantages and limitations in the application of some simple quantitative methods. Microsc Microanal, 7, 253-264.

Hossler, F.E., Lametschwandtner, A., Kao, R. \& Finsterbusch, F. (2013). Microvascular architecture of mouse urinary bladder described with vascular corrosion casting, light microscopy, SEM, and TEM. Microsc Microanal 13, 1-8.

JACOB, R.E., Colby, S.M., Kabilan, S., Einstein, D.R. \& CARson, J.P. (2013). In situ casting and imaging of the rat airway tree for accurate 3D reconstruction. Exp Lung Res, 39, 249-257.

Jamous, M.A., Nagahiro, S., Kitazato, K.T., Satoh, K. \& Satomi, J. (2005). Vascular corrosion casts mirroring early morphological changes that lead to the formation of saccular cerebral aneurysm: An experimental study in rats. J Neurosurg, 102, 532-535. 
JAUng, R., CooK, P. \& Blyth, P. (2011). A comparison of embalming fluids for use in surgical workshops. Clin Anat, 24, 155-561.

John, B., Ghani, K.R., Patel, U. \& Anson, K. (2008). Resin polymer and corrosion casting of the porcine pelvi-calyceal system: a useful model for investigating new imaging and endoscopic techniques of the upper urinary tract. Urol Res, 36, 39-42.

KaChliK, D., BACA, V. \& STINGL, J. (2010). The spatial arrangement of the human large intestinal wall blood circulation. J Anat, 216, 335-343.

Kappler, U.A., Constantinescu, M.A., Buchler, U. \& Vogelin, E. (2005). Anatomy of the proximal cutaneous perforator vessels of the gracilis muscle. Brit J Plast Surg, 58, 445-448.

Kawarada, Y., Das, B.C., Onishi, H., Taoka, H., Gadziev, E.M., RAVNIK, D., TABATA, M. \& IsAJI, S. (2000). Surgical anatomy of the bile duct branches of the medial segment (B4) of the liver in relation to hilar carcinoma. J Hepatobiliary Pancreat Surg, 7, 480-485.

Kaya, A.H., SAM, B., CeliK, F. \& TuRE, U. (2006). A quick-solidifying, coloured silicone mixture for injecting into brains for autopsy: Technical report. Neurosurg Rev, 29, 322-326. discusson 326.

Kemp, M. (2010). Style and non-style in anatomical illustration: From Renaissance Humanism to Henry Gray. J Anat, 216, 192-208.

Kerckaert, I., Van Hoof, T., Pattyn, P. \& D’Herde, K. (2008). Endogent: Centre for anatomy and invasive techniques. Anatomy, 2, 28-33.

Khot, Z., Quinlan, K., Norman, G.R. \& Wainman, B. (2013). The relative effectiveness of computer-based and traditional resources for education in anatomy. Anat Sci Educ, 6, 211-215.

Kolts, I., Tillmann, B. \& Lullmann-Rauch, R. (1994). The structure and vascularization of the biceps brachii long head tendon. Ann Anat, 176, 75-80.

Krucker, T., Lang, A. \& Meyer, E.P. (2006). New polyurethanebased material for vascular corrosion casting with improved physical and imaging characteristics. Microsc Res Tech, 69, 138-147.

Latorre, R., Vazquez, J.M., Gil, F., Ramirez, G., Lopez-Albors, O., Orenes, M., Martinez-Gomariz, F. \& Arenciba, A. (2001). Teaching anatomy of the distal equine thoracic limb with plastinated slices. J Int Soc Plastination, 16, 23-30.

LeISer, R. \& Pfarrer, C.D. (2005). Analysis of fetal and maternal microvasculature in ruminant placentomes by corrosion casting. In Placenta and Trophoblast: Methods and Protocols, Soares, M.J. \& Hunt, J.S. (Eds.), pp. 393-407. New York: Humana Press Inc.

Magden, O., Edizer, M., Atabey, A., TAyfur, V. \& Ergur, I. (2004). Cadaveric study of the arterial anatomy of the upper lip. Plast Reconstr Surg, 114, 355-359.

MaINA, J.N. \& van GiLS, P. (2001). Morphometric characterization of the airway and vascular systems of the lung of the domestic pig, Sus scrofa: Comparison of the airway, arterial and venous systems. Comp Biochem Physiol A Mol Integr Physiol, 130, 781-798.

Makanya, A., GachoKA, J. \& Kariuki, G.K. (2008). A short review of the methods used in museum technology. Bull Anim Health Prod Afr 56, 267-269.

Makanya, A.N. \& DJonov, V. (2008). Development and spatial organization of the air conduits in the lung of the domestic fowl, Gallus gallus variant domesticus. Microsc Res Tech, 71, 689-702.

MaKanya, A.N. \& Djonov, V. (2009). Parabronchial angioarchitecture in developing and adult chickens. J Appl Physiol, 106, 1959-1969.

Makanya, A.N., HlushchuK, R., Baum, O., Velinov, N., Ochs, M. \& Djonov, V. (2007). Microvascular endowment in the developing chicken embryo lung. Am J Physiol Lung Cell Mol Physiol, 292, L1136-L1146.
Makanya, A.N., Hlushchuk, R. \& Djonov, V.G. (2009). Intussusceptive angiogenesis and its role in vascular morphogenesis, patterning, and remodeling. Angiogenesis, 12, 113-123.

Makanya, A.N., Kavoi, B.M. \& Djonov, V. (2014). ThreeDimensional Structure and Disposition of the Air Conducting and Gas Exchange Conduits of the Avian Lung: The Domestic Duck (Cairina moschata). ISRN Anatomy, 2014, Article ID 621982, 9 pages, 2014. doi:10.1155/2014/621982.

Makanya, A.N., Sparrow, M.P., Warui, C.N., Mwangi, D.K. \& Burri, P.H. (2001). Morphological analysis of the postnatally developing marsupial lung: The quokka wallaby. Anat Rec, 262, 253-265.

Makanya, A.N., Stauffer, D., Ribatti, D., Burri, P.H. \& Djonov, V. (2005). Microvascular growth, development, and remodeling in the embryonic avian kidney: The interplay between sprouting and intussusceptive angiogenic mechanisms. Microsc Res Tech, 66, 275-288.

Masset, A., Staszyk, C. \& Gasse, H. (2006). The blood vessel system in the periodontal ligament of the equine cheek teeth-Part I: The spatial arrangement in layers. Ann Anat, 188, 529-533.

McKeon, K.E., Wright, R.W., Johnson, J.E., McCormick, J.J. \& KLEIN, S.E. (2012). Vascular anatomy of the tibiofibular syndesmosis. J Bone Joint Surg Am, 94, 931-938.

MEYER, E.P. (1989). Corrosion casts as a method for investigation of the insect tracheal system. Cell Tissue Res, 256, 1-6.

Meyer, E.P., Beer, G.M., Lang, A., Manestar, M., Krucker, T., Meier, S., Minic-Probst, D. \& Groscurth, P. (2007). Polyurethane elastomer: A new material for the visualization of cadaveric blood vessels. Clin Anat, 20, 448-454.

Meyer, E.P., Ulmann-Schuler, A., Staufenbiel, M. \& Staufenbiel, T. (2008). Altered morphology and 3D architecture of brain vasculature in a mouse model for Alzheimer's disease. $P$ Natl Acad Sci USA, 105, 3587-3592.

Minnich, B. \& Lametschwandtner, A. (2010). Scanning electron microscopy and vascular corrosion casting for the characterization of microvascular networks in human and animal tissues. In Microscopy: Science, Technology, Applications and Education, Méndez-Vilas, A. \& Díaz, J. (Eds.), pp. 29-39. Badajoz: Formatex.

Mulisch, M. \& WelsCh, U. (2010). Romeis Mikroskopische Technik. Heidelberg: Spektrum Akademischer Verlag.

Nikolic, V., Teofilovski-Parapid, G., Stankovic, G., Parapid, B., Malobabic, S. \& Stojic, V. (2004). Third coronary artery in monkey heart. Acta Vet Hung, 52, 253-257.

Ninomiya, H., Akiyama, E., SimaZaki, K., Oguri, A., Jitsumoto, M. \& Funuyama, T. (2011). Functional anatomy of the footpad vasculature of dogs: Scanning electron microscopy of vascular corrosion casts. Vet Dermatol, 22, 475-481.

Nöller, C., Henninger, W., Grönemeyer, D.H.W., Hirschberg, R.M. \& BUDRAS, K.D. (2006). Computed tomography: Anatomy of the normal feline nasolacrimal drainage system. Vet Radiol Ultrasoun, 47, 53-60.

Ohкuma, H., Iтон, K., Shibata, S., Suzuki, S. (1997). Morphological changes of intraparenchymal arterioles after experimental subarachnoid hemorrhage in dogs. Neurosurgery, 41, 230-235; discussion 235-236.

Onishi, H., Kawarada, Y., Das, B.C., Nakano, K., Gadzijev, E.M., RAVNIK, D. \& IsAJI, S. (2000). Surgical anatomy of the medial segment (S4) of the liver with special reference to bile ducts and vessels. Hepatogastroenterology, 47, 143-150.

Papakonstantinou, M.K., Pan, W.-R., Le Roux, C.M. \& Richardson, M.D. (2012). New approach to the study of intraosseous vasculature. Anz J Surg, 82, 704-707. 
PARKe, W.W. (2004). Arteriovenous glomeruli of the human spinal cord and their possible functional implications. Clin Anat, 17, 558-563.

Pereira-Sampaio, M.A., Henry, R.W., Favorito, L.A. \& Sampaio, F.J. (2012). Cranial pole nephrectomy in the pig model: anatomic analysis of arterial injuries in tridimensional endocasts. J Endourol, 26, 716-721.

Pereira-Sampaio, M.A., Marques-Sampaio, B.P., Sampaio, F.J. \& Henry, R.W. (2011). Shrinkage of renal tissue after impregnation via the cold Biodur plastination technique. Anat Rec, 294, 1418-1422.

Perry, S.F., Purohit, A.M., Boser, S., Mitchell, I. \& Green, F.H. (2000). Bronchial casts of human lungs using negative pressure injection. Exp Lung Res, 26, 27-39.

Pinar, Y.A., Bilge, O. \& Govsa, F. (2005). Anatomic study of the blood supply of perioral region. Clin Anat, 18, 330-339.

Pitynski, K., Litwin, J.A., Richter, P. \& Miodonski, A.J. (2012). Microvascular architecture of human epicolic and paracolic lymph nodes located in the vicinity of colon cancer: A SEM study of corrosion casts. Pathol Res Pract, 208, 94-99.

Plaisant, O., Sarrazin, J.L., Gillot, C. \& Lassau, J.P. (1998). Technique for injection of the lumbar vertebral venous plexuses employed in anatomic, computed tomography and magnetic resonance imaging studies. Surg Radiol Anat, 20, 113-118.

PollitT, C.C. \& Molyneux, G.S. (1990). A scanning electron microscopical study of the dermal microcirculation of the equine foot. Equine Vet J, 22, 79-87.

Preece, D., Williams, S.B., Lam, R. \& Weller, R. (2013). "Let's Get Physical": Advantages of a physical model over 3D computer models and textbooks in learning imaging anatomy. Anat Sci Educ, 6, 216-224.

Pulvertaft, R.J. (1950). Museum techniques; a review. J Clin Pathol, 3, 1-23.

Ravi, S.B. \& Bнат, V.M. (2011). Plastination: A novel, innovative teaching adjunct in oral pathology. J Oral Maxillofac Pathol, 15, 133-137.

Ravnik, D., Gadzijev, E., Sojar, M. \& Stanisavljevic, D. (1995). Models of the epigastric cavity, the liver vessels and bile ducts as an anamic and surgical teaching tool. Chirurg, 66, $448-451$.

Rees, M.J. \& Taylor, G.I. (1986). A simplified lead oxide cadaver injection technique. Plast Reconstr Surg, 77, 141-145.

Riepertinger, A. \& Heuckendorf, E. (1993). E20 Color-Injection and plastination of the brain. J Int Soc Plastination, 7, 8-12.

Sanan, A., Abdel Aziz, K.M., Janjua, R.M., van Loveren, H.R. \& Keller, J.T. (1999). Colored silicone injection for use in neurosurgical dissections: Anatomic technical note. Neurosurgery, 45, 1267-1271. discussion 1271-1264.

Santerre, J.P., Woodhouse, K., Laroche, G. \& Labow, R.S. (2005). Understanding the biodegradation of polyurethanes: From classical implants to tissue engineering materials. Biomaterials, 26, 7457-7470.

SedLmayr, J.C. \& WitMer, L.M. (2002). Rapid technique for imaging the blood vascular system using stereoangiography. Anat Rec, 267, 330-336.

Sen, T., Esmer, A.F., Acar, H.I., Karahan, S.T. \& Tuccar, E. (2011). Arterial vascularisation of the anterior perforated substance. Singapore Med J, 52, 410-414.

ShaAri, C.M., Gannon, P.J., Salmeron, J., Sanders, I.R.A. \& URKen, M.L. (1999). Tracheal transplantation: Defining the vascular territory of the canine cranial thyroid artery. Otolaryngol Head Neck Surg, 120, 180-183.

Shimizu, S., Tanaka, R., Rhoton, A.L. Jr., Fukushima, Y., Osawa, S., KaWashima, M., OKa, H. \& FujI, K. (2006). Anatomic dissection and classic three-dimensional documentation: A unit of education for neurosurgical anatomy revisited. Neurosurgery, 58, E1000. discussion E1000.

Sivrev, D., Kayriakov, J., Trifonov, Z., Djelebov, D. \& Atanasov, M. (1997). Combined plastination methods for Preparation of Improved ophthalmologic teaching models. J Int Soc Plastination 12, 12-14.

Smith, R. \& Rhoton, A.L. (1999). comment to: Sanan, A., Abdel Aziz, K. M., Janjua, R. M., van Loveren, H. R., Keller, J.T. Colored silicone injection for use in neurosurgical dissections: anatomic technical note. Neurosurgery, 45, 1272-1274.

Spalteholtz, W. (1914). Ueber das Durchsichtigmachen von menschlichen und tierischen praeparaten. Leipzig: Hirzel.

Stamatakis, G., KnuUtinen, U., Laitinen, K. \& Spyros, A. (2010). Analysis and aging of unsaturated polyester resins in contemporary art installations by NMR spectroscopy. Anal Bioanal Chem, 398, 3203-3214.

TANAKA, C., IDE, M. \& Junior, A. (2006). Anatomical contribution to the surgical construction of the sartorius muscle flap. Surg Radiol Anat, 28, 277-283.

TANAKA, Y. (1988). Synthesis and characterization of epoxides. In Epoxy Resins Chemistry and Technology, May, C.A. (Ed.), pp. 9-284. New York: Marcel Dekker.

TANG, M., YIN, Z. \& Morris, S.F. (2008). A pilot study on three-dimensional visualization of perforator flaps by using angiography in cadavers. Plast Reconstr Surg, 122, 429-437.

Thiel, W. (1992a). Die Konservierung ganzer Leichen in natürlichen Farben. Ann Anat, 174, 185-195.

Thiel, W. (1992b). Eine Arterienmasse zur Nachinjektion bei der Konservierung ganzer Leichen. Ann Anat, 174, 197-200.

Tiedemann, K. \& von Hagens, G. (1982). The technique of heart plastination. Anat Rec, 204, 295-299.

Tilotta, F., Lazaroo, B., Laujac, M.H. \& Gaudy, J.F. (2009). A study of the vascularization of the auricle by dissection and diaphanization. Surg Radiol Anat, 31, 259-265.

Tompsett, D.H. (1970). Anatomical Techniques. Edinburgh: E. \& S. Livingstone.

Twelves, D., Nerurkar, A., Osin, P., Ward, A., Isacke, C. \& Gui, G.H. (2012). The anatomy of fluid-yielding ducts in breast cancer. Breast Cancer Res Treat, 132, 555-564.

Vandeghinste, B., Trachet, B., Renard, M., Casteleyn, C., Staelens, S., Loeys, B., Segers, P. \& Vandenberghe, S. (2011). Replacing vascular corrosion casting by in vivo micro-CT imaging for building $3 \mathrm{D}$ cardiovascular models in mice. $\mathrm{Mol}$ Imag Biol 13, 78-86.

Verli, F.D., Rossi-Schneider, T.R., Schneider, F.L., Yurgel, L.S. \& DE SouZA, M.A. (2007). Vascular corrosion casting technique steps. Scanning, 29, 128-132.

von Hagens, G. (1979). Impregnation of soft biological specimens with thermosetting resins and elastomers. Anat Rec, 194, 247-255.

Waldmann, A. (2006). Darstellung der topographischen Anatomie der Vordergliedmaße der Ringeltaube (Columba Palumbus Palumbus; Linnaeus, 1758). Giessen: VVB Laufersweiler-Verlag.

Walker, E.J., Shen, F., Young, W.L. \& Su, H. (2011). Cerebrovascular casting of the adult mouse for $3 \mathrm{D}$ imaging and morphological analysis. $J$ Vis Exp, 57, e2958. 
Walter, T.J., Sparks, E.E. \& HupPert, S.S. (2012). Threedimensional resin casting and imaging of mouse portal vein or intrahepatic bile duct system. J Vis Exp, 68, e4272.

Weiglein, A.H. (1997). Plastination in the neurosciences. Keynote lecture. Acta Anat, 158, 6-9.

Westerweel, P.E., RoOKMAaker, M.B., van ZonNeVeld, A.-J., Bleys, R.L. A.W., RabelinK, T.J. \& VerhaAr, M.C. (2005). A study of neovascularization in the rat ischemic hindlimb using Araldite casting and Spalteholtz tissue clearing. Cardiovasc Pathol, 14, 294-297.

Wiltse, L.L. \& PAIT, T.G. (1998). Herophilus of Alexandria (325-255 BC.). The father of anatomy. Spine (Phila Pa 1976), 23, 1904-1914.

Whuk, M., Hlushchuk, R., Janot, M., Tuffin, G., MartinyBaron, G., Holzer, P., Imbach-Weese, P., Djonov, V. \& HuynhDo, U. (2012). Podocyte EphB4 signaling helps recovery from glomerular injury. Kidney Int, 81, 1212-1225.

Wnuk, M., Hlushchuk, R., Tuffin, G., Huynh-Do, U. \& Djonov, V. (2011). The effects of PTK787/ZK222584, an inhibitor of
VEGFR and PDGFRbeta pathways, on intussusceptive angiogenesis and glomerular recovery from Thyl.1 nephritis. Am J Pathol, 178, 1899-1912.

Worthen, D.M. \& Wickham, M.G. (1972). Scanning electron microscopy tissue preparation. Invest Ophthalmol Vis Sci, 11, 133-136.

Ye, X., Rozen, W.M., Alonso-Burgos, A. \& Ashton, M.W. (2012). "Choke" vessels between vascular territories of the abdominal wall: Literature review and rare case of Leriche's syndrome. Clin Anat, 25, 998-1004.

Zhao, J.G., FenG, G.S., Kong, X.Q., Li, X., Li, M.H. \& Cheng, Y.S. (2004). Changes of tumor microcirculation after transcatheter arterial chemoembolization: First pass perfusion MR imaging and Chinese ink casting in a rabbit model. World $J$ Gastroenterol, 10, 1415-1420.

Zhuang, Y.H., Zheng, H.P., Lin, S.Q. \& Xu, D.C. (2011). Vasculature at the medial aspect of the foot and clinical application of flaps based on it for forefoot reconstruction. Plast Reconstr Surg, 127, 1967-1978. 